\title{
Disiloxanediolates and Metallasilsesquioxanes of the Rare Earth Elements
}

\begin{tabular}{|r|l|}
\hline Journal: & Zeitschrift für Anorganische und Allgemeine Chemie \\
\hline Manuscript ID: & zaac. 201000188.R1 \\
\hline Wiley - Manuscript type: & Research Report \\
\hline Date Submitted by the \\
Author: & 02-Jun-2010 \\
\hline Complete List of Authors: & $\begin{array}{l}\text { Edelmann, Frank; Otto-von-Guericke-Universität Magdeburg, } \\
\text { Lehrstuhl für Anorganische Chemie }\end{array}$ \\
\hline Keywords: & $\begin{array}{l}\text { Lanthanides, Disiloxanediolates, Silsesquioxanes, } \\
\text { Metallasilsesquioxanes, Crystal Structures }\end{array}$ \\
\hline
\end{tabular}

\section{s scholarONE \\ Manuscript Central}




\title{
RESEARCH REPORT
}

\section{Disiloxanediolates and Metallasilsesquioxanes of the Rare Earth Elements}

\author{
Volker Lorenz, Anja Edelmann, Stephan Gießmann, Cristian Hrib, Steffen Blaurock \\ and Frank T. Edelmann**a]
}

Dedicated to Professor Herbert W. Roesky on the Occasion of his 75th birthday

Keywords: Lanthanides; Disiloxanediolates; Silsesquioxanes; Metallasilsesquioxanes; Crystal Structures

\footnotetext{
* $\quad$ Prof. Dr. Frank T. Edelmann

Fax: +49-391-6712933

E-Mail: frank.edelmann@ovgu.de

[a] Chemisches Institut der Otto-von-Guericke-Universität Magdeburg Universitätsplatz 2, 39106 Magdeburg, Germany
} 


\begin{abstract}
This research report summarizes recent results in the chemistry of lanthanide disiloxanediolates and metallasilsesquioxanes. Both classes of compound can be regarded as realistic model compounds for silica-supported lanthanide catalysts.
\end{abstract}

\title{
1. Heterobimetallic siloxanediolates of the lanthanides
}

The chemistry of metallasiloxanes derived from silanediols, disiloxanediols and related $\mathrm{Si}-\mathrm{OH}$ species continues to be an area of vigorous research activities [1-7] because such compounds are valuable precursors for metal oxides and silicates [2,3] as well as models for silica-supported heterogeneous catalysts [1,4], or are catalytically active themselves [5]. A particularly useful ligand in this field is the tetraphenyldisiloxanediolate dianion, $\left[\left(\mathrm{Ph}_{2} \mathrm{SiO}\right)_{2} \mathrm{O}\right]^{2-}$, which gives rise to a variety of unusual and unexpected structures with alkali metals [6] and early transition metals [6,7]. The starting material 1,1,3,3tetraphenyl-1,3-disiloxanediol, $\mathrm{Ph}_{2} \mathrm{Si}(\mathrm{OH}) \mathrm{OSiPh}_{2}(\mathrm{OH})$ (1), is readily accessible from cheap precursors. Hydrolysis of $\mathrm{Ph}_{2} \mathrm{SiCl}_{2}$ in the presence of $\left(\mathrm{NH}_{4}\right)_{2} \mathrm{CO}_{3}$ affords $\mathrm{Ph}_{2} \mathrm{Si}(\mathrm{OH}) \mathrm{OSiPh}_{2}(\mathrm{OH})$ in yields up to $51 \%$. Minor by-products in this synthesis are diphenylsilanediol, $\mathrm{Ph}_{2} \mathrm{Si}(\mathrm{OH})_{2}(2,6 \%)$ and hexaphenyltrisiloxanediol, $\mathrm{Ph}_{2} \mathrm{Si}(\mathrm{OH}) \mathrm{O}-$ $\mathrm{SiPh}_{2} \mathrm{OSiPh}_{2}(\mathrm{OH})(\mathbf{3}, 18 \%)$ [8]. Group 3 metal (Sc, Y) and lanthanide complexes containing the $\left[\left(\mathrm{Ph}_{2} \mathrm{SiO}\right)_{2} \mathrm{O}\right]^{2-}$ ligand have been investigated mainly in our laboratory [9].

\subsection{Lanthanide(III) disiloxanediolates}

\section{a) Lanthanide(III) mono(disiloxanediolates)}

By now, the chemistry of lanthanide bis(disiloxanediolates) is well established, and some lanthanide tris(disiloxanediolates) have also been prepared and structurally characterized (vide infra) [9]. Only the synthesis of mono-substituted rare earth metal complexes derived from difunctional siloxanediolate ligands had not been achieved until recently. Thus far only one compound of this type has been synthesized and structurally 
characterized [10]. A reaction of anhydrous $\mathrm{YbCl}_{3}$ with in situ prepared $\left(\mathrm{Ph}_{2} \mathrm{SiOLi}\right)_{2} \mathrm{O}(4)$ (molar ratio 1:1) in THF solution gave a colorless product which analyzed well for the mono-substituted species $\left[\left(\mathrm{Ph}_{2} \mathrm{SiO}\right)_{2} \mathrm{O}\right] \mathrm{YbCl}(\mathrm{THF})_{3}$, but an unambiguous structural characterization failed thus far due to the lack of suitable single-crystals. We then reasoned that the closely related 1,1,3,3,5,5-hexaphenyl-1,3,5-trisiloxanediolate ligand would perhaps be a better suitable candidate for preparing a mono-substituted ytterbium species. 1,1,3,3,5,5-hexaphenyl-1,3,5-trisiloxanediol (3), like its lighter homologue $\mathbf{1}$ is readily available from the same reaction, i.e. the controlled hydrolysis of dichlorodiphenylsilane [8]. The preparation of the first mono(trisiloxanediolate) complex of a lanthanide element was achieved according to Scheme 1 by allowing anhydrous $\mathrm{YbCl}_{3}$ to react first with 2 equivalents of $\mathrm{LiN}\left(\mathrm{SiMe}_{3}\right)_{2}$, followed by treatment of the intermediate "[( $\left.\left(\mathrm{Me}_{3} \mathrm{Si}\right)_{2} \mathrm{~N}\right]_{2} \mathrm{YbCl}$ " with 3 in a 1:1 molar ratio. Crystallization from the concentrated reaction mixture afforded the mono(trisiloxanediolate) complex $\left[\mathrm{Ph}_{2} \mathrm{Si}\left(\mathrm{OSiPh}_{2} \mathrm{O}\right)_{2}\right] \mathrm{Yb}(\mathrm{THF})(\mu-\mathrm{Cl})_{3} \mathrm{Li}_{2}(\mathrm{THF})_{4}(\mathbf{5})$ in the form of colorless crystals in $93 \%$ isolated yield (determined after the crystal structure had been established).

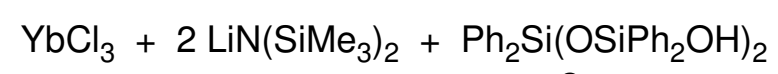

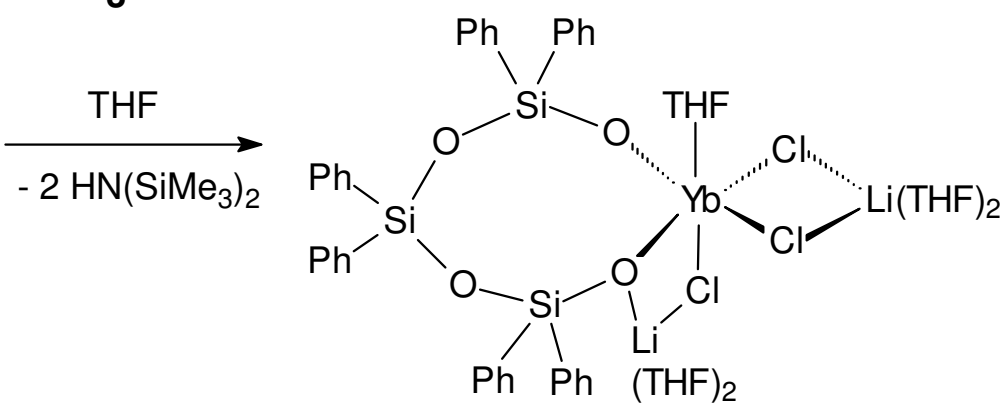

5

\section{Scheme 1}

An X-ray study confirmed the presence of the first mono(trisiloxanediolate) complex of a lanthanide element. The molecule contains a puckered eight-membered 
$\mathrm{Si}_{3} \mathrm{O}_{4} \mathrm{Yb}$ ring system resulting from coordination of the 1,1,3,3,5,5-hexaphenyl-1,3,5trisiloxanediolate dianion to ytterbium in a chelating fashion. Complexes containing chelating 1,1,3,3,5,5-hexaphenyl-1,3,5-trisiloxanediolate have previously been reported e.g. for hafnium and uranium [6,7,9]. In these cases, however, the trisiloxanediolate ligand is formed by ring-enlargement reactions starting from disiloxanediolate precursors. A prominent structural feature of compound $\mathbf{5}$ is the presence of a so-called "ate" complex resulting from retention of lithium chloride. "Ate" complexes are a common phenomenon in organolanthanide chemistry. Their formation involves retention of alkali halides formed during the course of a reaction, thereby reflecting the strong tendency of the large lanthanide ions to achieve high coordination numbers [11]. In compound $\mathbf{5}$ the situation is such that a complex of the type "[ $\left.\mathrm{Ph}_{2} \mathrm{Si}\left(\mathrm{OSiPh}_{2} \mathrm{O}\right)_{2}\right] \mathrm{YbCl}$ is sterically highly unsaturated (coordination number 3 at $\mathrm{Yb}$ ). In this case stabilitzation is achieved not only by coordination of one THF ligand but also through "ate" complex formation with retention of two equivalents of $\mathrm{LiCl}$. One lithium chloride is connected to the central ytterbium via two bridging chloride ligands. The second $\mathrm{LiCl}$ is coordinated in a rather peculiar way by additional coordination of a siloxide oxygen atom to Li. In both cases, the coordination sphere around lithium is supplemented by two THF ligands (Fig. 1) [10]. 


\section{b) Lanthanide(III) bis(disiloxanediolates)}

Heterobimetallic Group 3 metal (Sc, Y) and lanthanide complexes containing two $\left[\left(\mathrm{Ph}_{2} \mathrm{SiO}\right)_{2} \mathrm{O}\right]^{2-}$ ligands form the largest and most thoroughly investigated group of compounds in this area [9]. It was found that the small $\mathrm{Sc}^{3+}$ and $\mathrm{Y}^{3+}$ ions form heterobimetallic complexes in which the Group 3 metal fits into the center of a twelvemembered $\mathrm{Si}_{4} \mathrm{O}_{6} \mathrm{Li}_{2}$ inorganic ring system formed by two lithium disiloxanediolate units. Additional chloro functionalities and solvent molecules are arranged in the trans-positions. Accordingly these complexes have been termed "metallacrown" derivatives of scandium and yttrium [9]. In contrast, large $\mathrm{Ln}^{3+}$ ions such as $\mathrm{Pr}^{3+}, \mathrm{Nd}^{3+}$ or $\mathrm{Sm}^{3+}$ do no fit into the center of the twelve-membered $\mathrm{Si}_{4} \mathrm{O}_{6} \mathrm{Li}_{2}$ inorganic ring system but are significantly displaced, leading to a series of bis(disiloxanediolate) complexes which have been termed "inorganic lanthanide metallocenes" [9]. It was shown that this new class of heterobimetallic lanthanide disiloxanediolates (Scheme 2a) shares structural similarities 
with the well-known bent metallocenes containing pentamethylcyclopentadienyl $\left(=\mathrm{C}_{5} \mathrm{Me}_{5}\right)$ ligands (Scheme 2b). The latter form a large and well-investigated class of organolanthanides with many of them displaying high catalytic activities in various olefin transformations [11]. In both cases two bulky ligands are coordinated to the central lanthanide ion in a bent geometry, leaving room for functionalities $\mathrm{X}\left(\mathrm{X}=\mathrm{Cl}, \mathrm{N}\left(\mathrm{SiMe}_{3}\right)_{2}\right.$, alkyl, $\mathrm{H}$ etc.) as well as additional solvent molecules $\mathrm{S}\left(\mathrm{S}=\mathrm{Et}_{2} \mathrm{O}\right.$, THF etc.).

a)

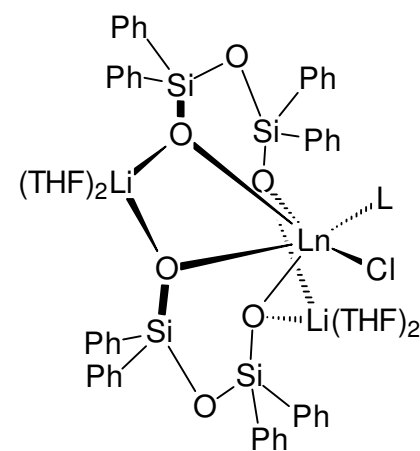

b)

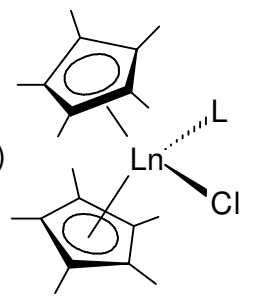

\section{Scheme 2}

The preparation of heterobimetallic disiloxanediolates of scandium and yttrium was performed as illustrated in Schemes 3 and 4 . In the first step, $\mathrm{ScCl}_{3}(\mathrm{THF})_{3}$ or anhydrous $\mathrm{YCl}_{3}$ were allowed to react with $\mathrm{LiN}\left(\mathrm{SiMe}_{3}\right)_{2}$ in order to produce in situ the "ate"complexes $\left[\left(\mathrm{Me}_{3} \mathrm{Si}\right)_{2} \mathrm{~N}\right]_{3} \mathrm{M}(\mu-\mathrm{Cl}) \mathrm{Li}(\mathrm{THF})_{3}$ [12]. Addition of 2 equivalents of $\mathbf{1}$ to the resulting reaction mixtures produced colorless or slightly yellowish solutions from which the new heterobimetallc disiloxanediolates $\left[\left\{\left(\mathrm{Ph}_{2} \mathrm{SiO}\right)_{2} \mathrm{O}\right\}_{2}\{\mathrm{Li}(\mathrm{DME})\}_{2}\right] \mathrm{ScCl}(\mathrm{THF} / \mathrm{DME})$ (6) and $\left[\left\{\left(\mathrm{Ph}_{2} \mathrm{SiO}\right)_{2} \mathrm{O}\right\}_{2}\left\{\mathrm{Li}(\mathrm{THF})_{2}\right\}_{2}\right] \mathrm{YCl}(\mathrm{THF})$ (7) could be prepared in high yields (6: $81 \%, 7: 77 \%)$. The Sc derivative 6 was isolated in the form of colorless, needle-like crystals, while the Y complex 7 forms colorless blocks. Both are soluble in THF and DME, but virtually insoluble in hydrocarbon solvents. 


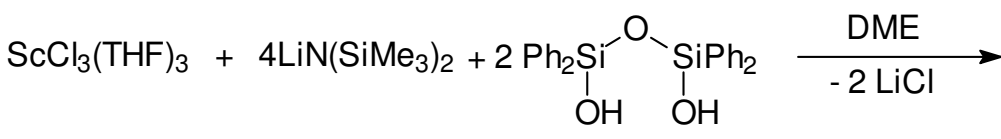

$$
\begin{aligned}
& 1
\end{aligned}
$$

\section{Scheme 3}

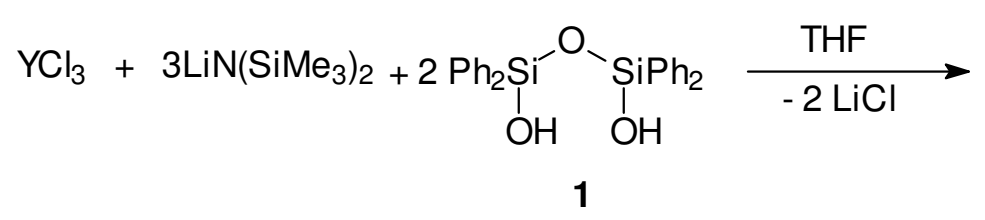

In the solid-state structure of $\mathbf{6}$ the central scandium adopts a distorted octahedral coordination geometry. Due to the use of $\mathrm{ScCl}_{3}(\mathrm{THF})_{3}$ as starting material and carrying out the reaction in DME both solvent molecules in $\mathbf{6}$ are coordinated to scandium with a statistical disorder of $c a .40 / 60$ (THF/DME). The coordinated DME ligand is bonded in a monodentate fashion. One of the DME ligands coordinated to Li is also disordered. One oxgen of the coordinated solvent and a chloride ligand occupy the trans-positions. With $178.30(5)^{\circ}$ the $\mathrm{Cl}(1)-\mathrm{Sc}(1)-\mathrm{O}(9)$ unit is almost linear. An inorganic $\left[\left\{\left(\mathrm{Ph}_{2} \mathrm{SiO}\right)_{2} \mathrm{O}\right\}_{2^{-}}\right.$ $\left.\{\mathrm{Li}(\mathrm{DME})\}_{2}\right]^{2-}$ ring system is wrapped around the $\mathrm{Sc}^{3+}$ ion in an equatorial plane like a metallacrown ether ligand. The most important result of this structural study was the finding that the scandium derivative $\mathbf{6}$ does not fit into the concept of "inorganic metallocenes". Obviously the ionic radius of $\mathrm{Sc}^{3+}(0.885 \AA$ for coordination number 6$)$ is 
small enough to fit into the cavity of the $\left[\left\{\left(\mathrm{Ph}_{2} \mathrm{SiO}\right)_{2} \mathrm{O}\right\}_{2}\{\mathrm{Li}(\mathrm{DME})\}_{2}\right]^{2-}$ ligand system so that in this case the in-plane metallacrown form is clearly favored [9d].

An X-ray crystal structure determination of the yttrium complex $\left[\left\{\left(\mathrm{Ph}_{2} \mathrm{SiO}\right)_{2} \mathrm{O}\right\}_{2^{-}}\right.$ $\left.\left\{\mathrm{Li}(\mathrm{THF})_{2}\right\}_{2}\right] \mathrm{YCl}(\mathrm{THF})(7)\left(\right.$ Fig. 2) revealed a similar result for $\mathrm{Y}^{3+}$ (ionic radius $1.040 \AA$ for coordination number 6). This compound too adopts the metallacrown type structure with nearly octahedral coordination, although the larger $\mathrm{Y}^{3+}$ ion is not contained as perfectly in the metallacrown as the smaller $\mathrm{Sc}^{3+}$. Again the oxgen of the coordinated THF ligand and a chloride ligand occupy the trans-positions [9d].

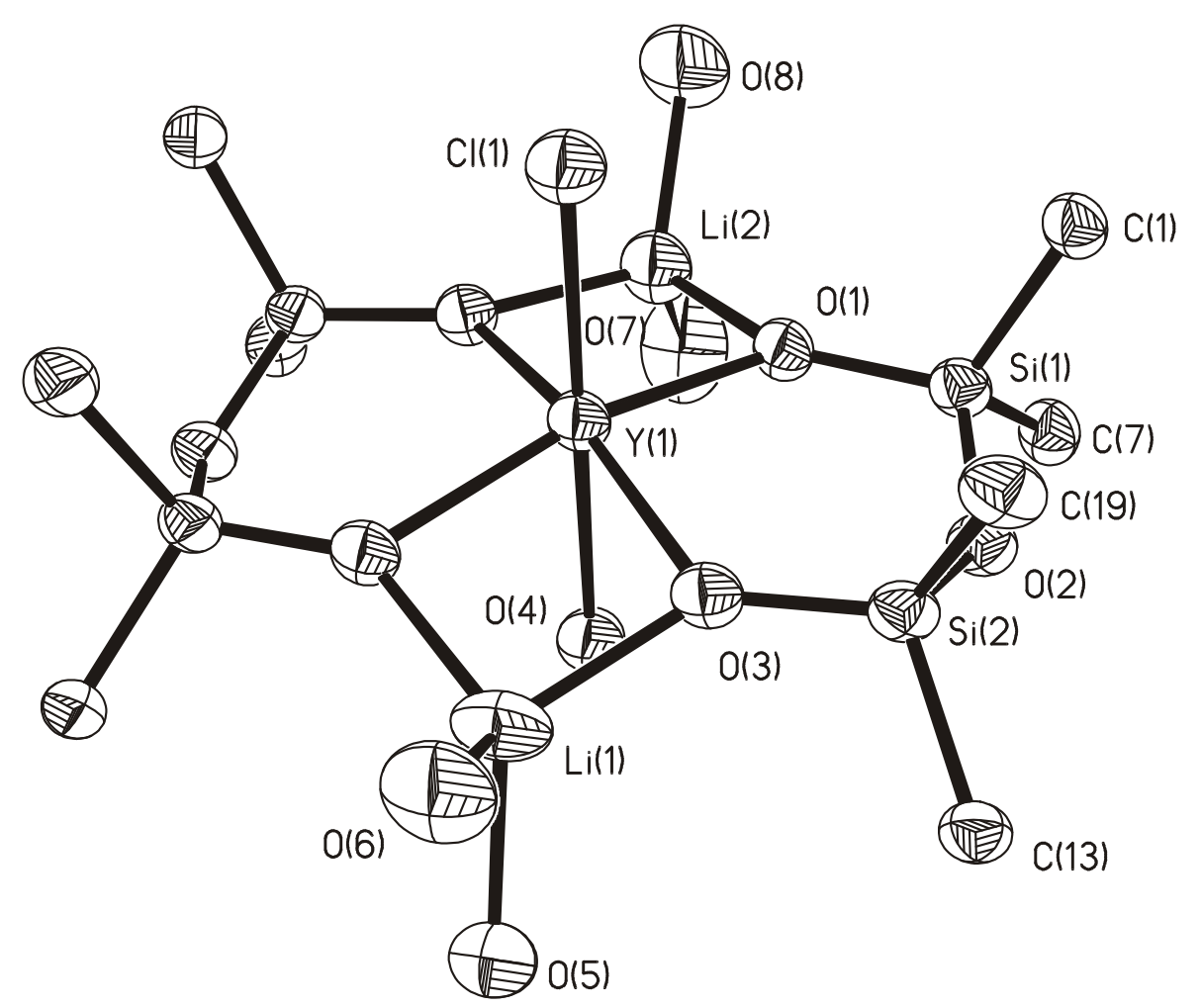

Figure 2. Molecular structure of 7 [9d]. For clarity, only the ipso carbon atoms of the phenyl substituents and the oxygen atoms of the THF ligands at Li are shown. 
In the case of holmium and erbium, the THF-adducts $\left[\left\{\left(\mathrm{Ph}_{2} \mathrm{SiO}\right)_{2} \mathrm{O}\right\}_{2}\left\{\mathrm{Li}(\mathrm{THF})_{2}\right\}_{2}\right]-$ $\mathrm{HoCl} \cdot 2 \mathrm{THF}(\mathbf{8 a}$, pale pink rods, $70 \%$ yield $)$ and $\left[\left\{\left(\mathrm{Ph}_{2} \mathrm{SiO}\right)_{2} \mathrm{O}\right\}_{2}\left\{\mathrm{Li}(\mathrm{THF})_{2}\right\}_{2}\right] \mathrm{ErCl} \cdot 2 \mathrm{THF}$ $(\mathbf{8 b}$, pale pink needles, $72 \%$ yield) were obtained according to Scheme 5 [9h].
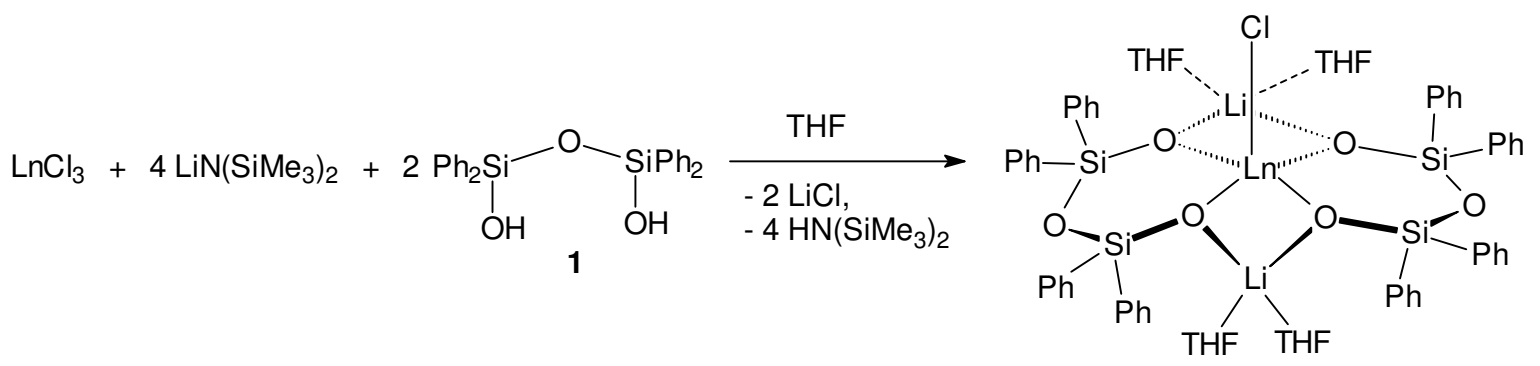

$\operatorname{Ln}=H_{0}(\mathbf{8 a}), \operatorname{Er}(\mathbf{8 b})$

\section{Scheme 5}

In both cases no meaningful NMR spectra could be obtained due to the strongly paramagnetic nature of the $\mathrm{Ho}^{3+}$ and $\mathrm{Er}^{3+}$ ions, respectively. However, the structural analyses revealed that due to the larger ionic radii of $\mathrm{Ho}^{3+}$ and $\mathrm{Er}^{3+}$ as compared to $\mathrm{Sc}^{3+}$ both complexes adopt the "inorganic metallocene" structural type. This means that the lanthanide metal is significantly displaced from the center of the twelve-membered $\mathrm{Si}_{4} \mathrm{O}_{6} \mathrm{Li}_{2}$ inorganic ring system formed by two lithium disiloxanediolate units. However, the use of these intermediate size lanthanide ions leads to formation of a new structural variety in that the molecules are "unsolvated", i.e. no solvent molecules are coordinated to the lanthanides. This is in contrast to the related $\mathrm{Pr}, \mathrm{Nd}$ and $\mathrm{Sm}$ derivatives (vide infra), in which the central lanthanide ion is large enough to leave room for an additional chelating DME ligand. Thus the new holmium and erbium derivatives represent an intermediate structural type of lanthanide bis(disiloxanediolates) between the "inorganic metallocenes" $(\mathrm{Pr}, \mathrm{Nd}, \mathrm{Sm})$ and the "metallacrowns" (Sc, Y). At present, however, we cannot offer a plausible explanation for the differences in the solid-state structures of the $\mathrm{Ho} / \mathrm{Er}$ complexes $8 \mathbf{a}$ and $\mathbf{8 b}$ on one hand and the related yttrium complex $\mathbf{7}$ on the other, 
especially as there are no significant differences in the ionic radii between these metals. Two lithium disiloxanediolate units are connected to form a twelve-membered $\mathrm{Si}_{4} \mathrm{O}_{6} \mathrm{Li}_{2}$ metallacycle to which the lanthanide ion is coordinated in an out-of-plane fashion. The coordination sphere around the lanthanide is completed by a single chloro-functionality with no room left for additional solvent molecule coordination.

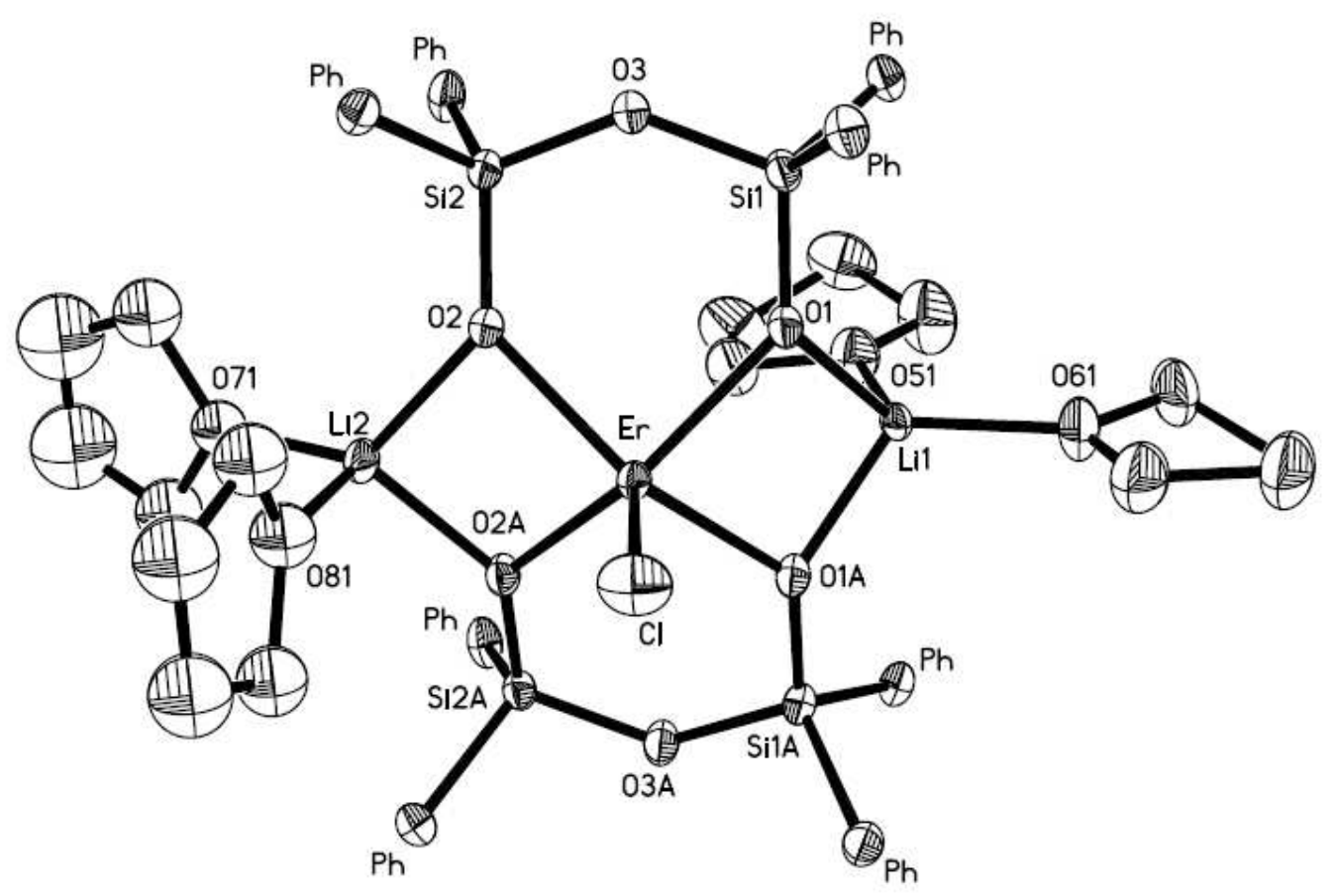

Figure 3. Molecular structure of $\left[\left\{\left(\mathrm{Ph}_{2} \mathrm{SiO}\right)_{2} \mathrm{O}\right\}_{2}\left\{\mathrm{Li}(\mathrm{THF})_{2}\right\}_{2}\right] \mathrm{ErCl} \cdot 2 \mathrm{THF}(\mathbf{8 b})[9 \mathrm{~h}]$. For clarity, only the ipso carbon atoms of the phenyl substituents are shown.

A first compound containing additional coordinated solvent was the samarium complex $\left[\left\{\left(\mathrm{Ph}_{2} \mathrm{SiO}\right)_{2} \mathrm{O}\right\}_{2}\{\mathrm{Li}(\mathrm{DME})\}_{2}\right] \mathrm{SmCl}(\mathrm{DME})$ (9) which was prepared by allowing anhydrous $\mathrm{SmCl}_{3}$ to react with 3 equivalents of $\mathrm{LiN}\left(\mathrm{SiMe}_{3}\right)_{2}$ in order to produce in situ the "ate" complex $\left[\left(\mathrm{Me}_{3} \mathrm{Si}\right)_{2} \mathrm{~N}\right]_{3} \mathrm{Sm}(\mu-\mathrm{Cl}) \mathrm{Li}(\mathrm{THF})_{3} \quad(\mathbf{1 0})$ which was then treated with 2 equivalents of $\mathbf{1}$. Praseodymium and neodymium were also employed as representatives of the larger early lanthanide elements. The ionic radius of $\operatorname{Pr}^{3+}$ in hexacoordinate complexes 
is $1.13 \AA$. The reactions leading to the first praseodymium disiloxanediolates are summarized in Scheme 6. [\{( $\left.\left.\left.\mathrm{Ph}_{2} \mathrm{SiO}\right)_{2} \mathrm{O}\right\}_{2}\left\{\mathrm{Li}(\mathrm{THF})_{2}\right\}\{\mathrm{Li}(\mathrm{THF})\}\right] \operatorname{Pr}(\mu-\mathrm{Cl})_{2} \mathrm{Li}(\mathrm{THF})_{2}(\mathbf{1 1})$ was prepared in the same way as the Sm derivative 9 and isolated in $68 \%$ yield in the form of colorless platelets.

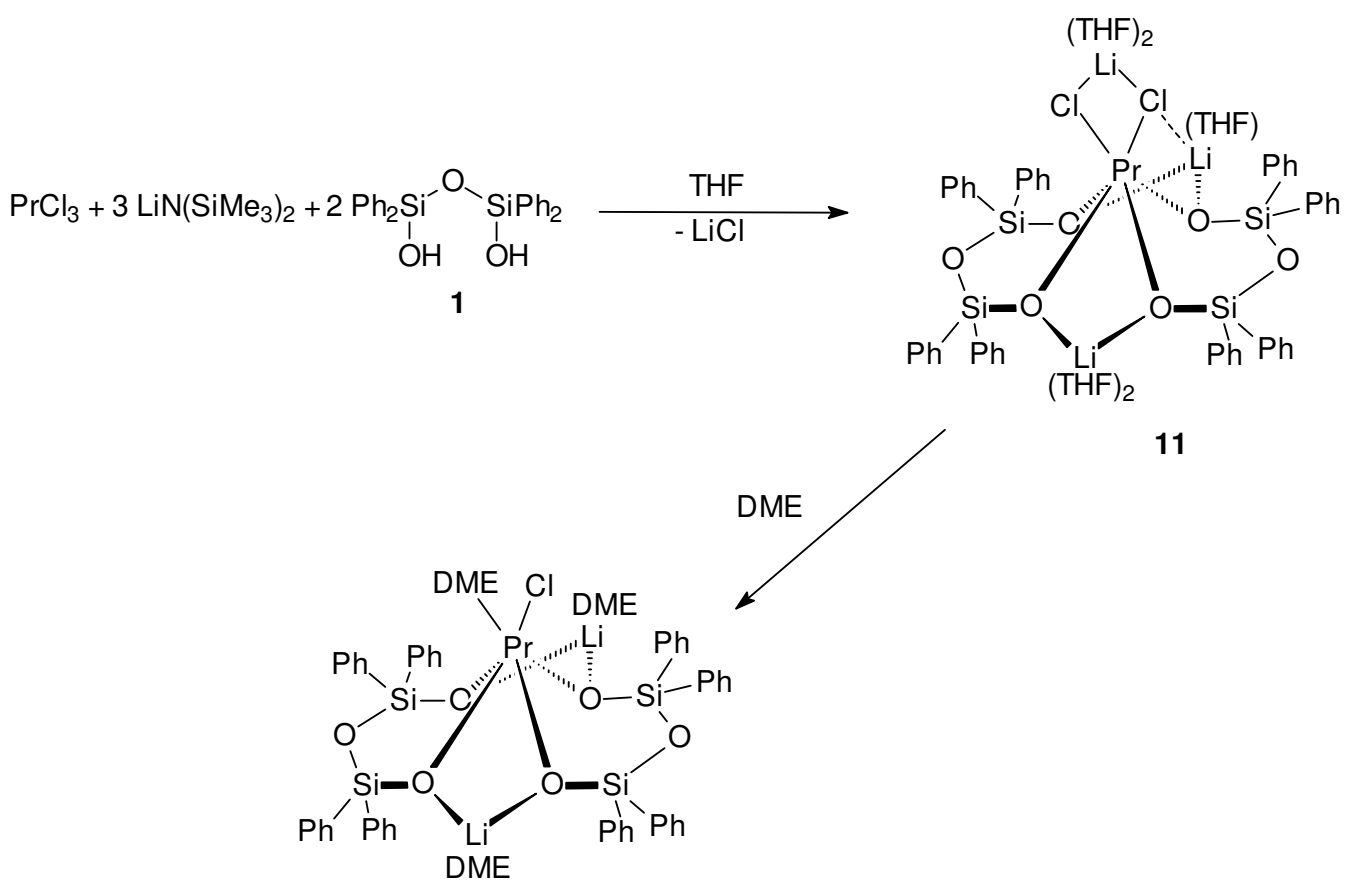

12

\section{Scheme 6}

A single-crystal X-ray diffraction study of $\mathbf{1 1}$ revealed the presence of a heterobimetallic praseodymium disiloxanediolate which fits into the concept of "inorganic metallocenes". This result clearly demonstrated the dependence of the molecular structures of these compounds on the ionic radius of the central $\mathrm{Ln}^{3+}$ ion. In $\mathbf{1 1}$ the $\left[\left\{\left(\mathrm{Ph}_{2} \mathrm{SiO}\right)_{2} \mathrm{O}\right\}_{2}\left\{\mathrm{Li}(\mathrm{THF})_{2}\right\}\{\mathrm{Li}(\mathrm{THF})\}\right]^{2-}$ ligand system is coordinated to praseodymium in a slightly bent arrangement, because the $\mathrm{Pr}^{3+}$ ion is too large to fit into the cavity of the metallacrown. As a consequence, the additional ligands are forced into the cis-positions. 
Retention of $\mathrm{LiCl}$ leads to formation of a typical "ate" complex in which $\mathrm{Pr}$ and $\mathrm{Li}$ are connected via two bridging chloro ligands (Fig. 4).

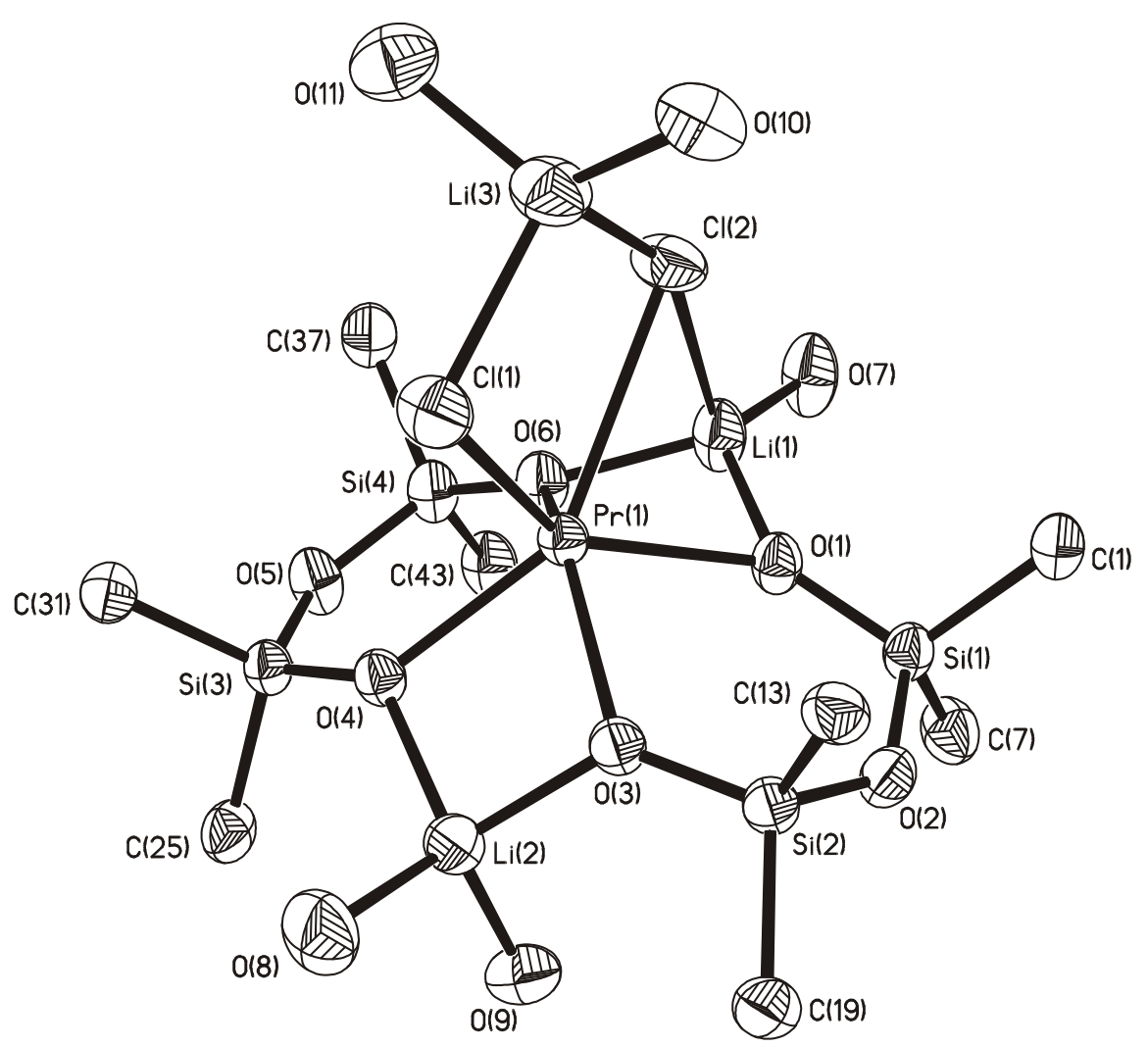

Figure 4. Molecular structure of $\mathbf{1 1}$ [9d]. For clarity, only the ipso carbon atoms of the phenyl substituents and the oxygen atoms of coordinated THF are shown.

As depicted in Scheme 7, this type of complexes is quite common in the chemistry of bis(pentamethylcyclopentadienyl)lanthanide complexes [11]. The molecular structure of 11 nicely demonstrates the structural relationship between the "inorganic metallocenes" or out-of-plane metallacrowns with their well-known $\mathrm{C}_{5} \mathrm{Me}_{5}$ counterparts. 

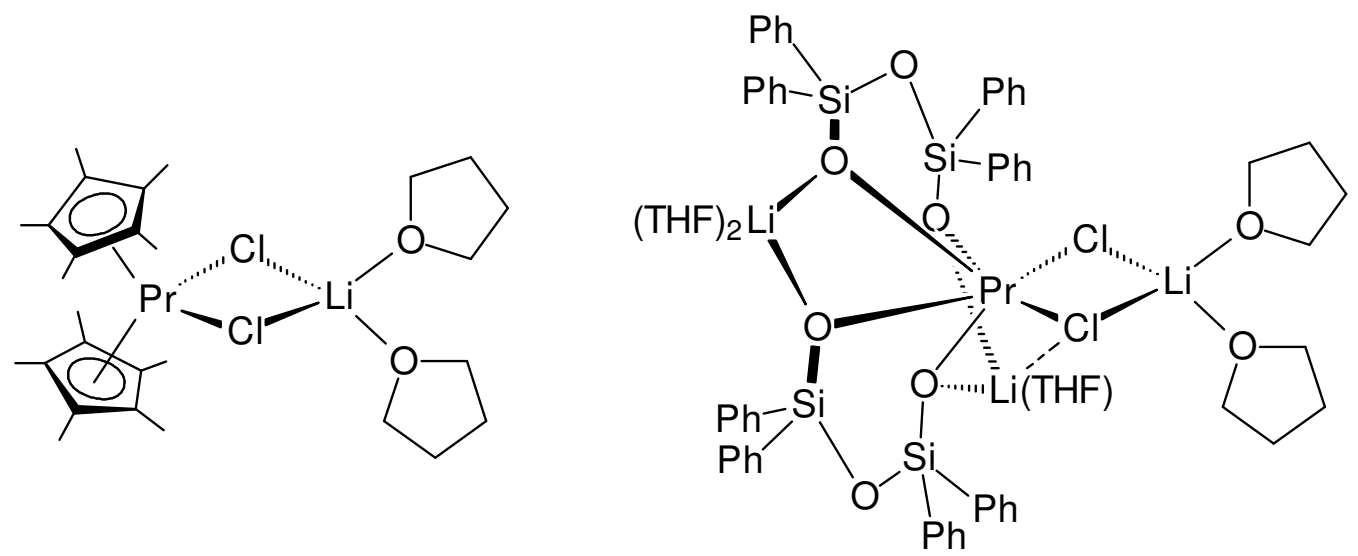

\section{Scheme 7}

In contrast to the trans-arrangement of the chloride and solvent ligands in $\mathbf{6}$ and $\mathbf{7}$, the $\mathrm{Cl}$ ligands in $\mathbf{1 1}$ are in cis-positions. One $\mathrm{Li}$ is coordinated by two THF molecules, while the other one has only one THF ligand. In the latter case there is an additional weaker $\mathrm{Li}-\mathrm{Cl}$ interaction with a distance of $2.667(6) \AA$. Due to this weak $\mathrm{Li}-\mathrm{Cl}$ bond the overall structure of $\mathbf{1 1}$ approaches a trigonal-prismatic coordination geometry. The most important result of the crystal structure determination of $\mathbf{1 1}$ is the fact that this compound too can be regarded as an "inorganic metallocene" or out-of-plane metallacrown complex. The coordinated $\mathrm{LiCl}$ can be removed by recrystallization of $\mathbf{1 1}$ from DME as illustrated in Scheme 6. This resulted in formation of the neutral complex $\left[\left\{\left(\mathrm{Ph}_{2} \mathrm{SiO}\right)_{2} \mathrm{O}\right\}_{2}\{\mathrm{Li}(\mathrm{DME})\}_{2}\right] \operatorname{PrCl}(\mathrm{DME})(\mathbf{1 2})$ with heptacoordinate praseodymium. Here again the praseodymium is coordinated to the $\left[\left\{\left(\mathrm{Ph}_{2} \mathrm{SiO}\right)_{2} \mathrm{O}\right\}_{2}\{\mathrm{Li}(\mathrm{DME})\}_{2}\right]^{2-}$ ligand system in a an out-of-plane arrangement. Thus the compound also belongs to the group of "inorganic metallocenes". A terminal chloride ligand and a chelating DME complete the coordination sphere around praseodymium. The overall coordination geometry can be best described as monocapped trigonal-prismatic. The analogous neodymium derivative $\left[\left\{\left(\mathrm{Ph}_{2} \mathrm{SiO}\right)_{2} \mathrm{O}\right\}_{2}\{\mathrm{Li}(\mathrm{DME})\}_{2}\right] \mathrm{Nd}(\mathrm{DME}) \mathrm{Cl}(\mathbf{1 3})$ was obtained according to Scheme 8 in $75 \%$ yield in the form of pale pink crystal blocks. 


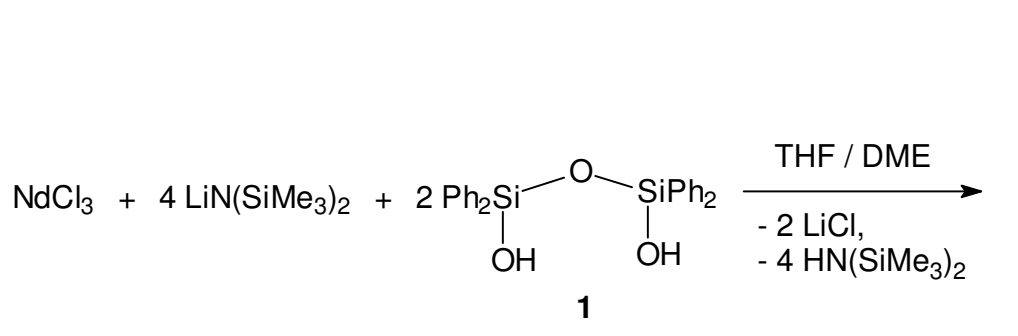

Scheme 8

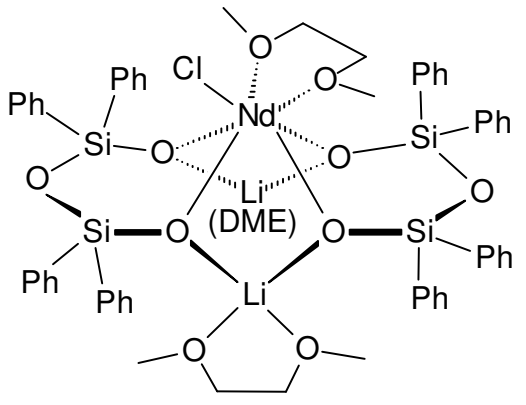

13

An X-ray analysis revealed that the compound is isostructural with the praseodymium(III) complex 12. By slightly changing the reaction conditions the reaction of anhydrous $\mathrm{PrCl}_{3}$ with 2 equivalents of $\left(\mathrm{Ph}_{2} \mathrm{SiOLi}\right)_{2} \mathrm{O}(\mathbf{4})$ (made in situ by treatment of $\mathbf{1}$ with 2 equivalents of $\left.\mathrm{LiN}\left(\mathrm{SiMe}_{3}\right)_{2}\right)$ according to Scheme 9 a new silylamide-functionalized complex, $\left[\left\{\left(\mathrm{Ph}_{2} \mathrm{SiO}\right)_{2} \mathrm{O}\right\}_{2}\left\{\mathrm{Li}(\mathrm{THF})_{2}\right\}_{2}\right] \operatorname{Pr}\left[\mathrm{N}\left(\mathrm{SiMe}_{3}\right)_{2}\right](\mathbf{1 4})$, became available:

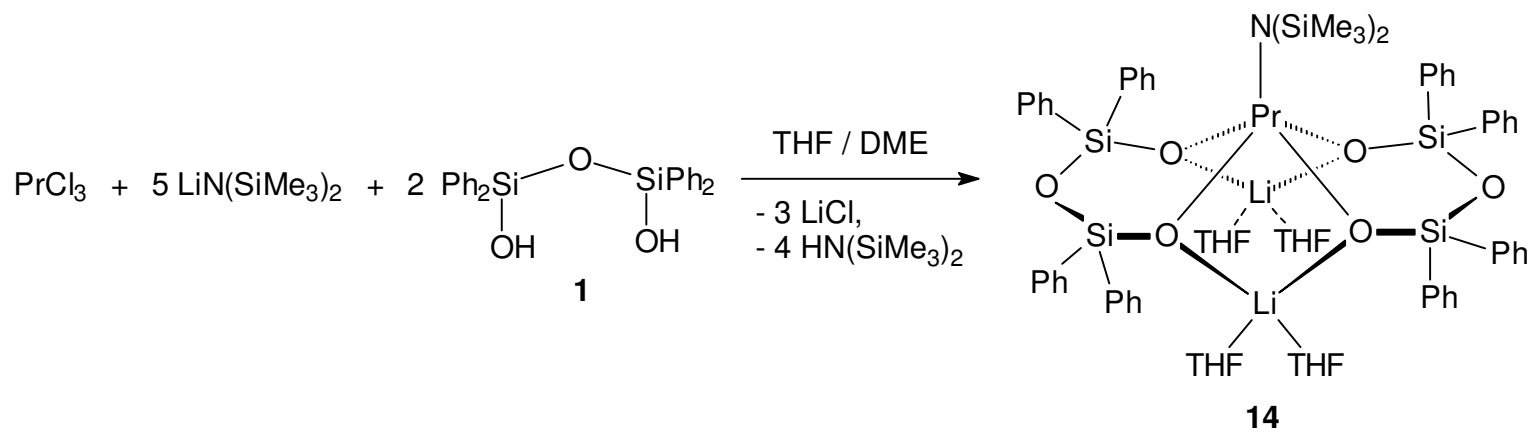

Scheme 9

The formation of $\mathbf{1 4}$ can be explained by the fact that an excess of $\mathrm{LiN}\left(\mathrm{SiMe}_{3}\right)_{2}(5$ equivalents) was used for the preparation of $\mathbf{1 1}$ instead of 3 equivalents as would be required. Thus it is likely that the silylamide $\mathbf{1 4}$ was formed by a metathetical reaction of an intermediate chloro derivative with the remaining equivalent of $\mathrm{LiN}\left(\mathrm{SiMe}_{3}\right)_{2}$. Thus far, however, more deliberate preparations of $\mathbf{1 4}$ by treatment of the chloro precursors $\mathbf{1 1}$ or $\mathbf{1 2}$ 
with $\mathrm{LiN}\left(\mathrm{SiMe}_{3}\right)_{2}$ failed due to the formation of complex product mixtures. Crystallization of $\mathbf{1 4}$ from a concentrated solution in THF yielded pale green crystals in $65 \%$ yield. An Xray analysis confirmed the presence of the silylamide-functionalized praseodymium bis(disiloxanediolate) complex. As expected, this compound too belongs to the class of "inorganic metallocene"-type lanthanide bis(disiloxanediolates) comprising an out-of-plane coordination of the $\mathrm{Ln}^{3+}$ ion to the twelve-membered $\mathrm{Si}_{4} \mathrm{O}_{6} \mathrm{Li}_{2}$ inorganic ring system formed by two lithium disiloxanediolate units. Only one closely related compound, the gadolinium(III) complex $\left[\left\{\left(\mathrm{Ph}_{2} \mathrm{SiO}\right)_{2} \mathrm{O}\right\}_{2}\left\{\mathrm{Li}(\mathrm{THF})_{2}\right\}_{2}\right] \mathrm{GdN}\left(\mathrm{SiMe}_{3}\right)_{2} \quad$ (15) had been reported earlier in the literature [9a,b]. This compound was prepared as outlined in Scheme 10.

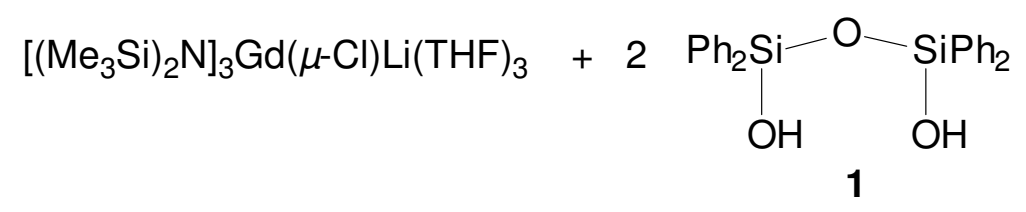

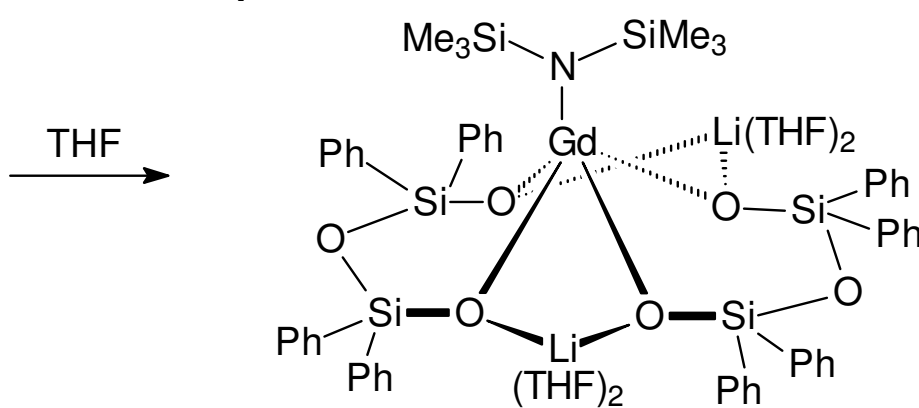

15

\section{Scheme 10}

In an attempt to prepare a disiloxanediolate complex of divalent samarium, $\mathbf{1}$ was first deprotonated using $\mathrm{NaN}\left(\mathrm{SiMe}_{3}\right)_{2}$ in THF solution to give $\left(\mathrm{Ph}_{2} \mathrm{SiONa}\right)_{2} \mathrm{O}(\mathbf{1 6})$, which was subsequently treated with samarium diiodide [9f]. When the reaction was carried out in refluxing THF, the dark blue-green color of $\mathrm{SmI}_{2}$ gradually faded, indicating oxidation under formation of samarium(III) species. Work-up and crystallization from the 
concentrated THF solution at $2{ }^{\circ} \mathrm{C}$ afforded light yellow, plate-like crystals in low yield (ca. $10 \%$, calculated after the structure had been established). A single-crystal X-ray analysis established the formation of the unprecedented heterobimetallic samarium(III) disiloxanediolate cluster $\left[\mathrm{Me}_{3} \mathrm{SiO}\{\mu-\mathrm{Na}(\mathrm{THF})\}_{3} \mathrm{Sm}\left\{\mu-\left(\mathrm{Ph}_{2} \mathrm{SiO}\right)_{2} \mathrm{O}\right\}_{3} \mathrm{Na}(\mathrm{THF})\right]$ (17). Thus the overall reaction sequence can be formulated as shown in Scheme 11 [9f].

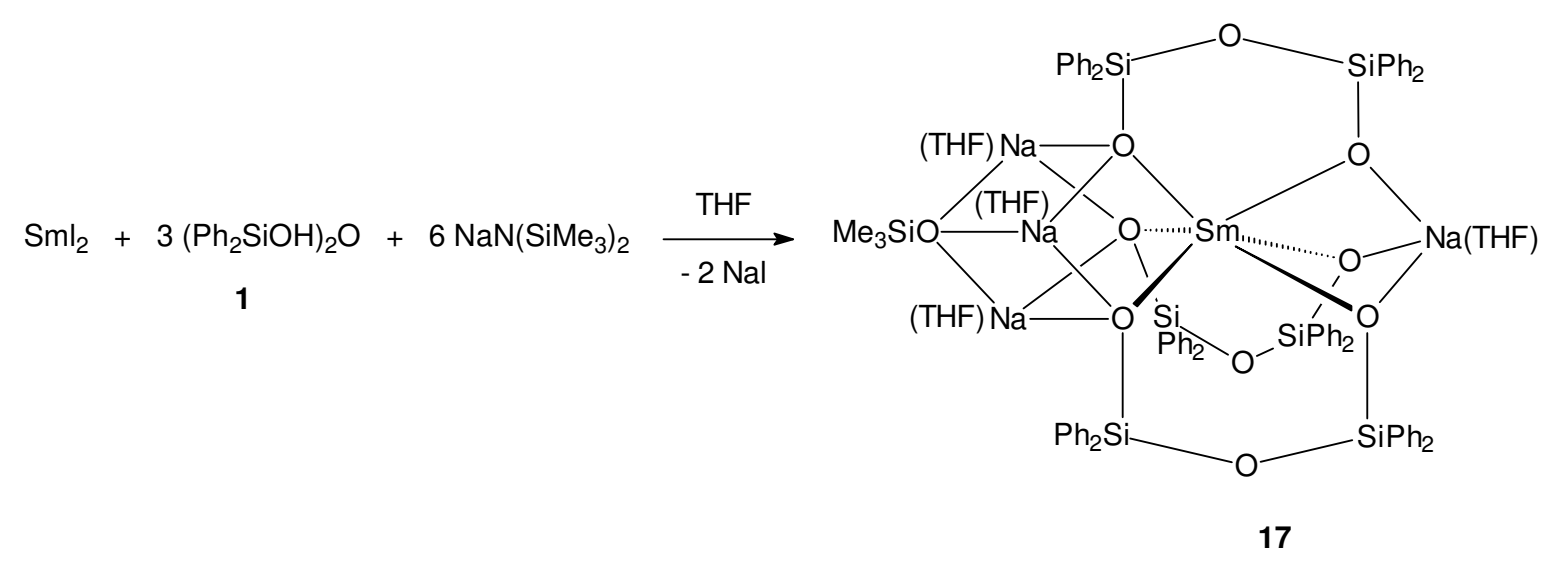

Scheme 11

The X-ray study confirmed the formation of a samarium(III) disiloxanediolate complex. In the solid state, compound $\mathbf{1 7}$ forms a polycyclic ring system which can be formally regarded as an "ate" complex derived from the hypothetical anionic species "[Na(THF) $]_{3}\left[\mathrm{Sm}^{3+}\left\{\left(\mathrm{Ph}_{2} \mathrm{SiO}\right)_{2} \mathrm{O}\right\}_{3}\right] "$. The "ate" complex results from addition of one equivalent of $\mathrm{Me}_{3} \mathrm{SiONa}(\mathrm{THF})$ to the salt-like complex. Although the mechanism of the formation of 17 remains speculative, the source of the $\mathrm{Me}_{3} \mathrm{SiO}^{-}$ligand can only be the $\mathrm{NaN}\left(\mathrm{SiMe}_{3}\right)_{2}$ reagent used for the deprotonation of the disiloxanediol precursor. The oxidation of samarium(II) diiodide in the course of a reaction like that shown in Scheme 11 is not unusual. A typical example is the reaction of $\mathrm{SmI}_{2}$ with two equivalents of $\mathrm{Li}\left[\mathrm{Ph}_{2} \mathrm{P}\left(\mathrm{NSiMe}_{3}\right)_{2}\right]$ which afforded the colorless samarium(III) "ate" complex $\left[\mathrm{Ph}_{2} \mathrm{P}\left(\mathrm{NSiMe}_{3}\right)_{2}\right]_{2} \mathrm{Sm}(\mu-\mathrm{I})_{2} \mathrm{Li}(\mathrm{THF})_{2}$ in $70 \%$ yield. [13] The low yield in the case of $\mathbf{1 7}$ can 
be traced back to the additional incorporation of the $\mathrm{Me}_{3} \mathrm{SiO}^{-}$anion, which is presumably only a side-product in this reaction.

In the complex molecule of $\mathbf{1 7}$ the central $\mathrm{Sm}^{3+}$ ion is coordinated in a nearly octahedral fashion by six oxygen atoms of three chelating disiloxanediolate ligands (Fig. 5) [9f]. The latter act simultaneously as bridging ligands between samarium and a single sodium on one side of the molecule. Here the coordination sphere of the tetracoordinate $\mathrm{Na}^{+}$ion is completed by one THF ligand. Samarium is also part of a $\mathrm{SmNa}_{3} \mathrm{O}_{4}$ heterocubane cage containing three disiloxanediolate oxygen atoms and the oxygen of the $\mathrm{Me}_{3} \mathrm{SiO}^{-}$ligand. Certainly the most remarkable structural feature of compound $\mathbf{1 7}$ is the incorporation of samarium into a heterocubane cage. Heterocubane structures are fairly rare in organolanthanide chemistry. Prominent examples include the phosphoraneiminato complexes (COT) $\mathrm{LnLi}_{3} \mathrm{Cl}_{2}\left(\mathrm{NPPh}_{3}\right)_{2}(\mathrm{THF})_{3} \quad\left(\mathrm{LnLi}_{3} \mathrm{Cl}_{2} \mathrm{~N}_{2}\right.$ heterocubanes) [14] and the organolanthanide imido complexes $\left[\left(\mathrm{C}_{5} \mathrm{H}_{4} \mathrm{SiMe}_{3}\right) \operatorname{Ln}\left(\mu_{3}-\mathrm{NCH}_{2} \mathrm{R}\right)\right]_{4}(\mathrm{Ln}=\mathrm{Y}, \mathrm{Lu} ; \mathrm{R}=\mathrm{Me}$, $\mathrm{Ph})\left(\mathrm{Ln}_{4} \mathrm{~N}_{4}\right.$ heterocubanes $)[15]$. 


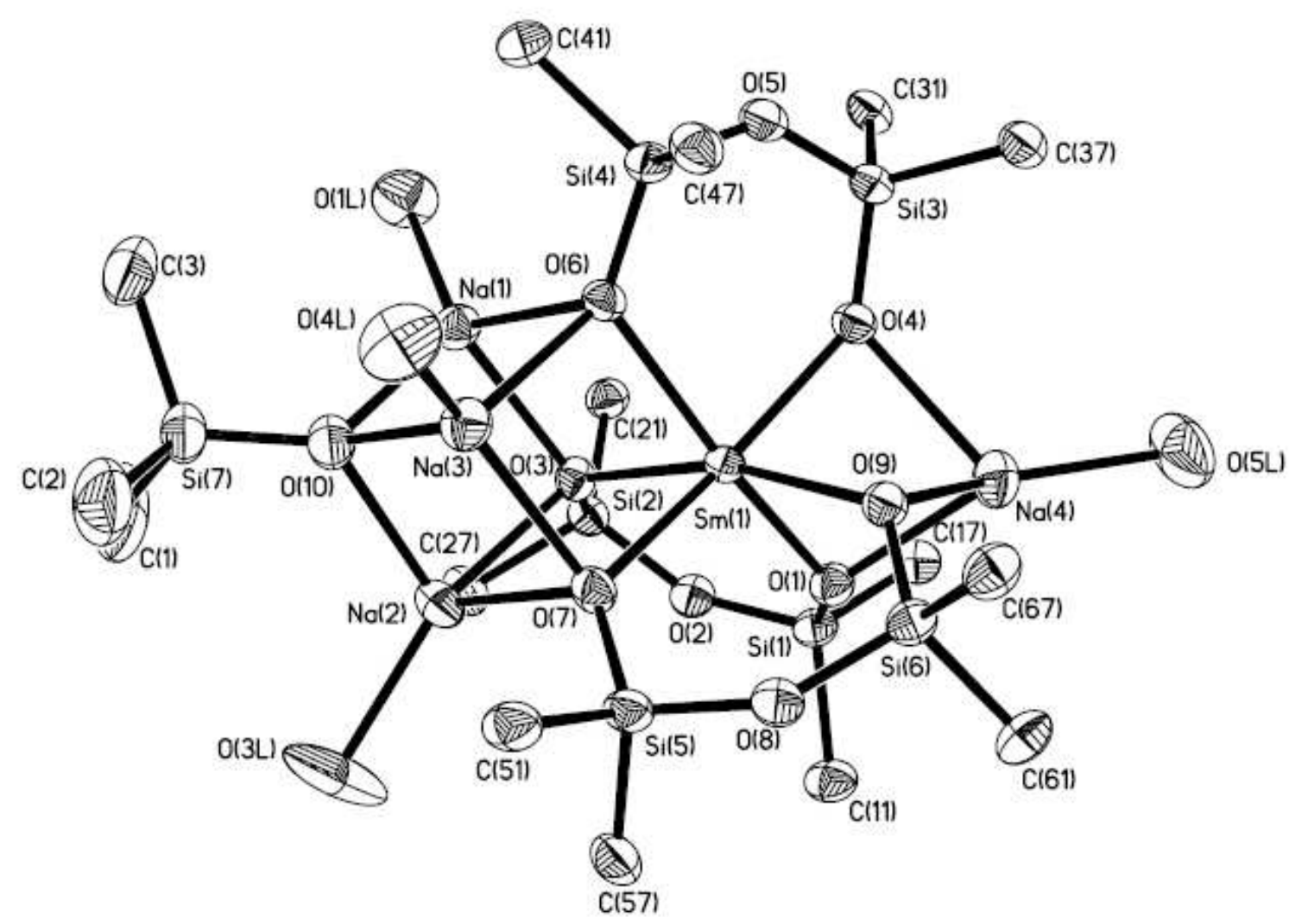

Figure 5. Molecular structure of $\left[\mathrm{Me}_{3} \mathrm{SiO}\{\mu-\mathrm{Na}(\mathrm{THF})\}_{3} \mathrm{Sm}\left\{\mu-\left(\mathrm{Ph}_{2} \mathrm{SiO}\right)_{2} \mathrm{O}\right\}_{3} \mathrm{Na}(\mathrm{THF})\right]($ 17) [9f]. For clarity, only the ipso carbon atoms of the phenyl substituents are shown.

A highly unusual inverse sandwich compound was obtained unexpectedly when the dimeric mono-COT precursor $\left[(\mathrm{COT}) \mathrm{Nd}(\mathrm{THF})_{2}(\mu-\mathrm{Cl})\right]_{2}$ was treated with in situ-prepared dilithium tetraphenyldisiloxanediolate, $\left(\mathrm{LiOSiPh}_{2}\right)_{2} \mathrm{O}(\mathbf{4})$, in a molar ratio of 1:4 (Scheme 12) [9i]. The reaction was carried out in THF solution. Work-up by extraction of the reaction mixture with diethyl ether followed by crystallization at $5{ }^{\circ} \mathrm{C}$ afforded pale blue, X-ray quality crystals in moderate yield (46\%, determined after the molecular structure had been established). Spectroscopic data (IR, NMR) provided only marginal information on the structure of the reaction product. Due to the paramagnetic nature of $\mathrm{Nd}^{3+}$ the ${ }^{1} \mathrm{H} \mathrm{NMR}$ spectrum of the product was not fully interpretable showing only signals for the phenyl protons of the tetraphenyldisiloxanediolate ligands. 


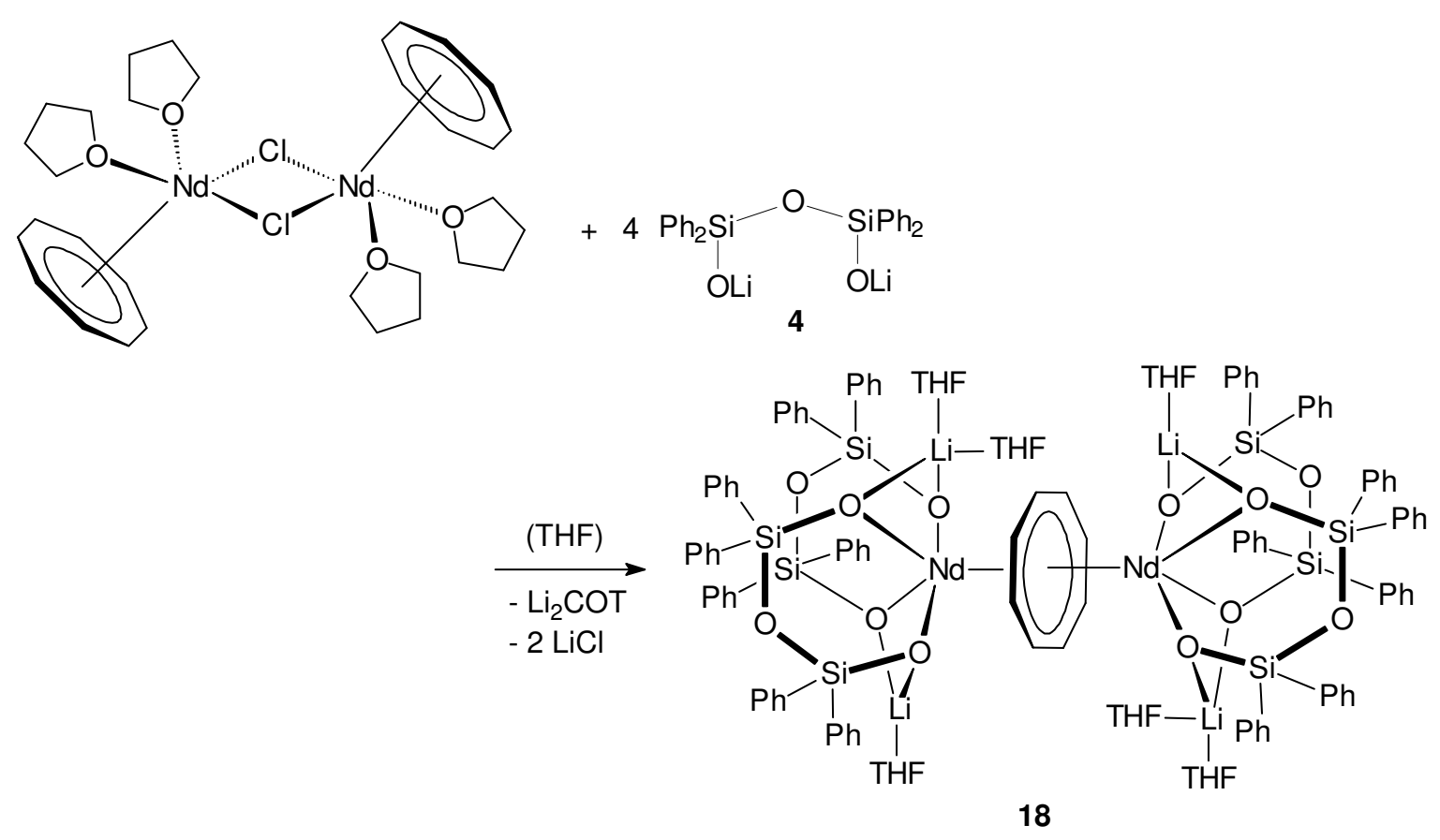

Scheme 12

A single-crystal X-ray diffraction study revealed the presence of an unprecedented organic/inorganic lanthanide triple-decker sandwich-complex, $\left(\mu-\eta^{8}: \eta^{8}-\mathrm{COT}\right)\left[\operatorname{Nd}\left\{\left(\mathrm{Ph}_{2} \mathrm{Si}\right.\right.\right.$ $\left.\left.\mathrm{O})_{2} \mathrm{O}\right\}_{2}\left\{\mathrm{Li}(\mathrm{THF})_{2}\right\}\{\mathrm{Li}(\mathrm{THF})\}\right]_{2}$ (18), in which the two $\mathrm{Nd}$ atomes are symmetrically bridged by a $\mu-\eta^{8}: \eta^{8}$-COT ligand (Fig. 6) [9i]. Like the inverse sandwich complexes $(\mu$ $\left.\eta^{8}: \eta^{8}-\mathrm{COT}\right)\left[\operatorname{Sm}\left\{\mathrm{N}\left(\mathrm{SiMe}_{3}\right)_{2}\right\}_{2}\right]_{2}[17]$ and $\left(\mu-\eta^{8}: \eta^{8}-\mathrm{COT}\right)\left[\operatorname{Sm}\left\{\mathrm{N}\left(\mathrm{SiMe}_{3}\right)\right\}(\mathrm{THF})_{2}\right]_{2}[18]$ the molecule contains an inversion center in the solid state with a Nd-(COT ring centroid)-Nd angle of $178.2^{\circ}$. The outer decks of the triple-decker sandwich structure in $\mathbf{1 8}$ are formed by twelve-membered $\mathrm{Si}_{4} \mathrm{O}_{6} \mathrm{Li}_{2}$ inorganic ring systems, each of them being composed of two lithium tetraphenyldisiloxanediolate units. Due to their large ionic radii, the $\mathrm{Nd}^{3+}$ ions are significantly displaced from the center of the twelve-membered rings. Quite surprisingly, the disiloxanediolate rings in $\mathbf{1 8}$ differ from those in the related mononuclear complexes in that the two $\mathrm{Li}^{+}$ions are differently solvated. Each of the ring ligands contains a tricoordinate $\mathrm{Li}(\mathrm{THF})$ unit and a tetracoordinate lithium with two THF ligands attached to lithium. However, the observation of only one ${ }^{29} \mathrm{Si}$ NMR resonance at $\delta=-46.4$ 
ppm indicates that this asymmetry is not retained in THF- $d_{8}$ solution, but that coordination of additional THF leads to a more symmetrical structure. It seems plausible that the reason for the different coordination modes around the $\mathrm{Li}^{+}$ions in the solid state is steric congestion in 18 which becomes evident from a space-filling view of the molecular structure. This view also gave a good impression of how phenyl groups of the opposite disiloxanediolate interlock, thereby encapsulating the central $\mu-\eta^{8}: \eta^{8}$-COT ligand like "a golden ring in a silicate box" [9h].

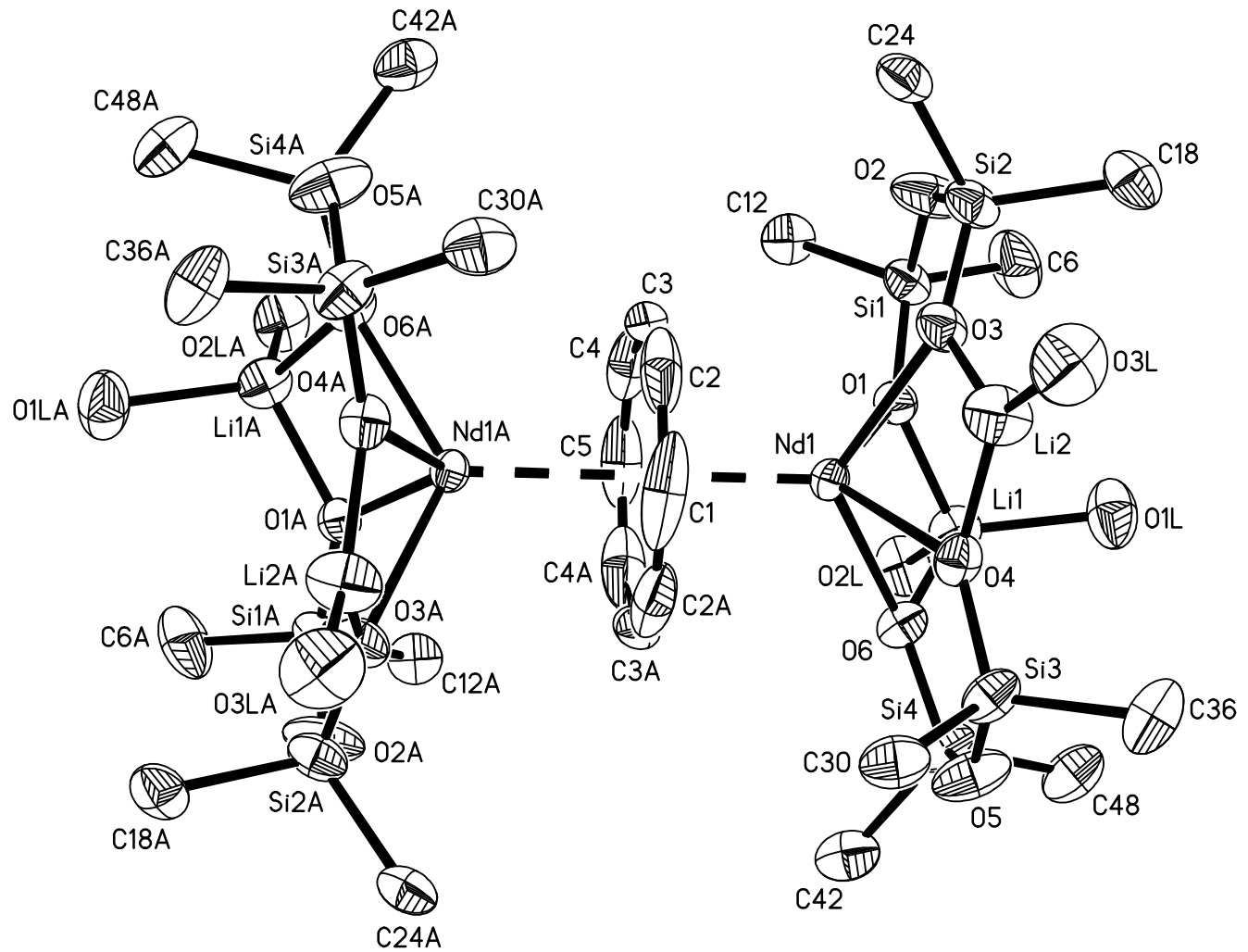

Figure 6. Molecular structure of $\left(\mu-\eta^{8}: \eta^{8}-\mathrm{COT}\right)\left[\mathrm{Nd}\left\{\left(\mathrm{Ph}_{2} \mathrm{SiO}\right)_{2} \mathrm{O}\right\}_{2}\left\{\mathrm{Li}(\mathrm{THF})_{2}\right\}\{\mathrm{Li}(\mathrm{THF})\}\right]_{2}$ (18) [9i]. For clarity, only the ipso carbon atoms of the phenyl substituents and the oxygen atoms of coordinated THF are shown 


\section{c) Reactivity of lanthanide(III) bis(disiloxanediolates}

Initial experiments regarding the derivative chemistry of the new lanthanide bi(disiloxanediolates) have already produced some promising and unexpected results [9e,g]. For example, treatment of the scandium complex 6 (Scheme 3) with an excess of trimethylaluminum in toluene afforded a colorless solution from which colorless, blockshaped single crystals could be isolated in $50 \%$ yield. This reaction was initially performed with the aim of replacing the chloro ligand in trans-position by a methyl group. However, an X-ray crystal structure determination revealed the presence of a unique heterotrimetallic ( $\mathrm{Sc} / \mathrm{Al} / \mathrm{Li})$ disiloxanediolate complex 19 as illustrated in Scheme 13.

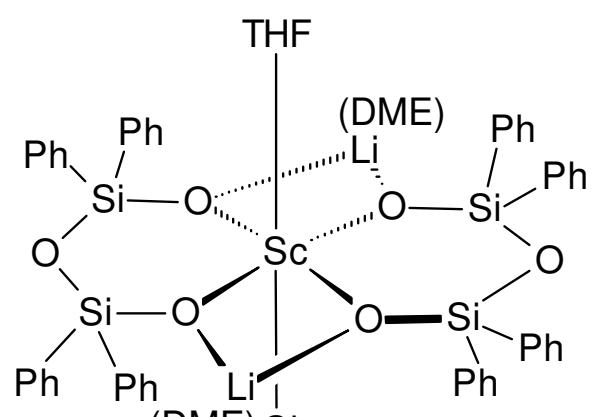

(DME) Cl

6

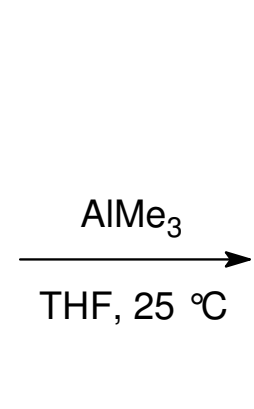

$\underset{\mathrm{THF}, 25{ }^{\circ} \mathrm{C}}{\stackrel{\mathrm{AlMe}_{3}}{\longrightarrow}}$

Scheme 13

The most surprising result of this reaction was the replacement of one $\mathrm{Li}(\mathrm{DME})^{+}$ unit in 6 by an $\mathrm{AlMe}_{2}^{+}$moiety under retention of the chloro function in trans-position. Despite the use of an excess of $\mathrm{AlMe}_{3}$ only one lithium was replaced. Like the starting material 6, the trimetallic product $\mathbf{1 9}$ too adopts the metallacrown form with the central $\mathrm{Sc}^{3+}$ ion accomodated well within the plane of the slightly puckered inorganic ring system. As in the starting material 6, one THF ligand and the chloride ion occupy the transpositions. The central metallacrown core is efficiently shielded by eight phenyl substituents 
and three coordinated THF molecules, which accounts for the high solubility of the complex in toluene (Fig. 7) [9e,g].

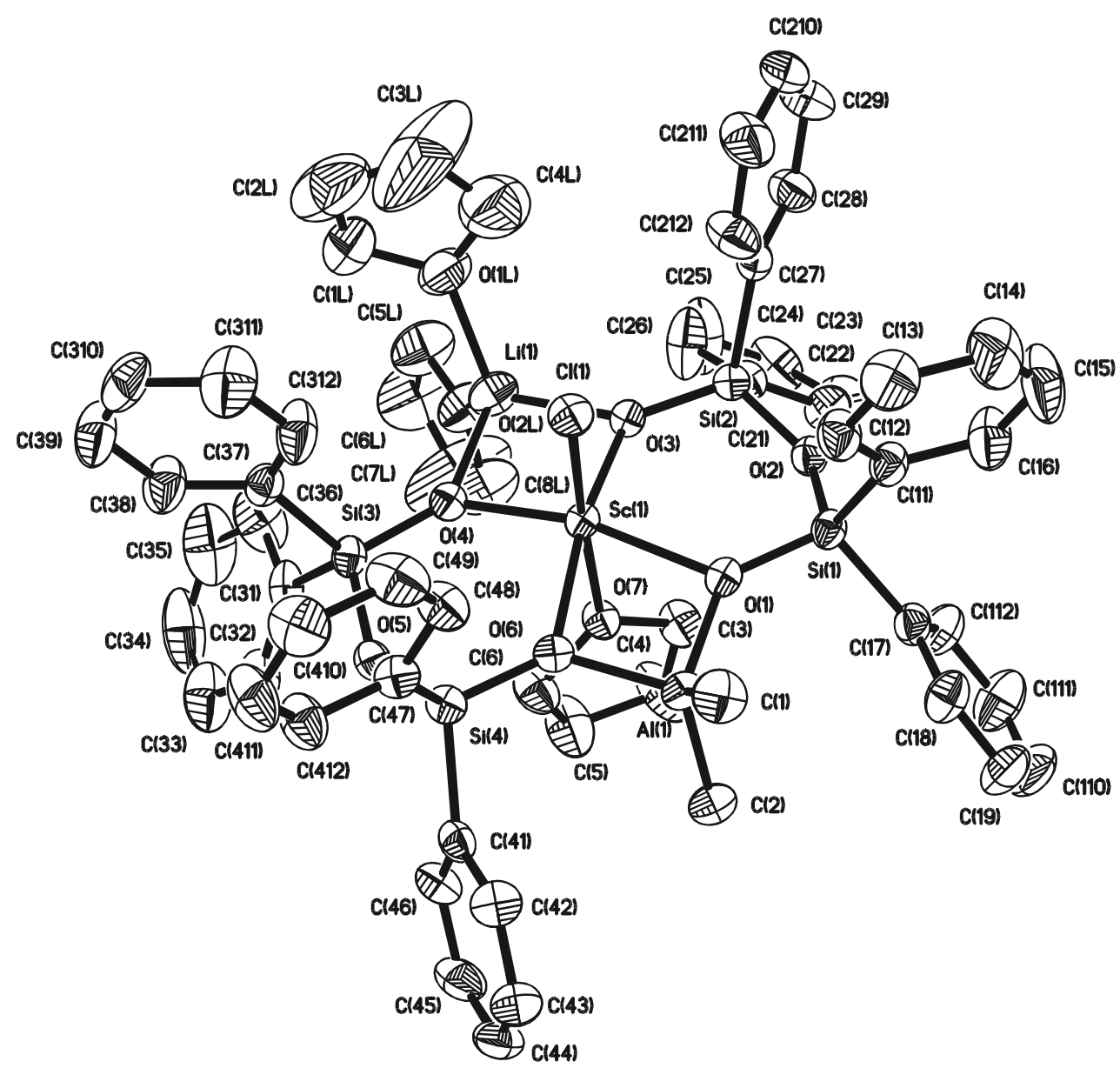

Figure 7. Molecular structure of $\left[\left\{\left(\mathrm{Ph}_{2} \mathrm{SiO}\right)_{2} \mathrm{O}\right\}_{2}\left\{\mathrm{Li}(\mathrm{THF})_{2}\right\} \mathrm{AlMe} \mathrm{Me}_{2} \mathrm{ScCl}(\mathrm{THF})(\mathbf{1 9})[9 \mathrm{e}]\right.$

A similar reaction carried out with the yttrium metallacrown precursor $\mathbf{7}$ and an excess of trimethylindium took an entirely different course [9e]. In this case colorless prism-shaped crystals were isolated in $81 \%$ yield by slow concentration of the filtered reaction mixture. An ${ }^{1} \mathrm{H}$ NMR spectrum of the product indicated the incorporation of three $\mathrm{InMe}_{2}$ units in two different ways (intensity ratio of the $\mathrm{InCH}_{3}$ resonances 2:1) and replacement of all coordinated THF. An X-ray diffraction study revealed the formation of a novel inorganic ring system 20 containing both yttrium and indium (Scheme 14). 


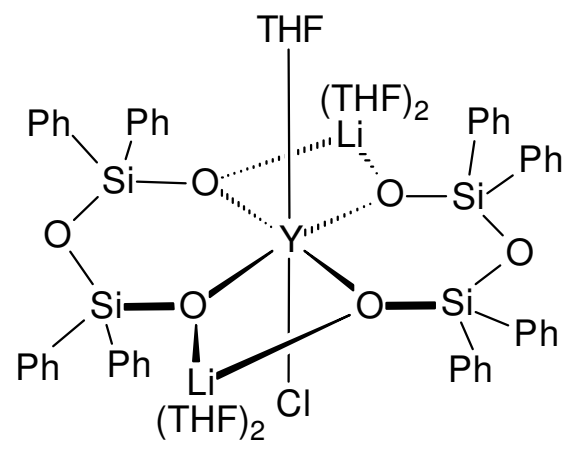

7

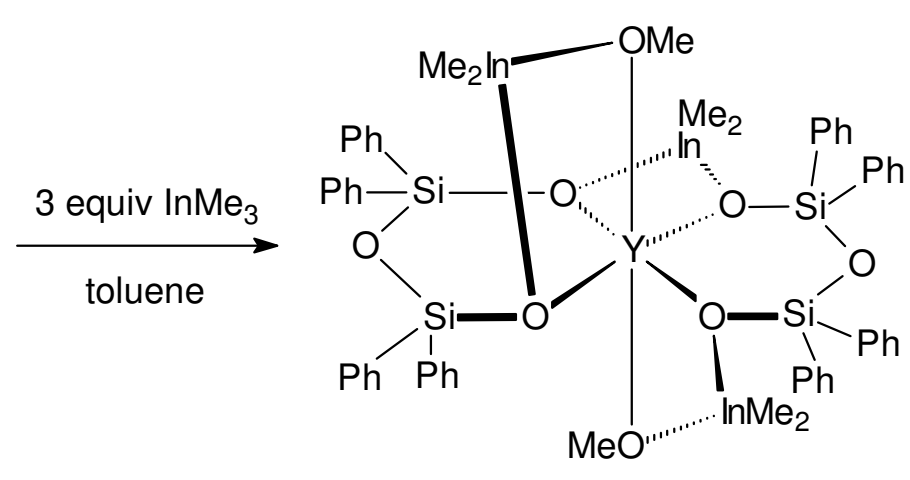

$20(81 \%)$

\section{Scheme 14}

In the molecular structure of $\mathbf{2 0}$ the central yttrium is coordinated by six oxygen atoms in a slightly distorted octahedral fashion. The crystal structure analysis confirmed the incorporation of three $\mathrm{InMe}_{2}{ }^{+}$moieties. One of them had replaced an $\mathrm{Li}(\mathrm{THF})_{2}{ }^{+}$unit within the metallacrown ring system, while the other two were converted into $\mathrm{Me}_{2} \mathrm{InOMe}$ ligands. The significantly lower solubility of $\mathbf{2 0}$ in toluene as compared to $\mathbf{1 9}$ can be traced back to the much less effective shielding of the "inorganic" metallacrown core by phenyl substituents. The most remarkable structural feature of $\mathbf{2 0}$, however, is the complex stabilization of two monomeric $\mathrm{Me}_{2} \mathrm{InOMe}$ ligands. Free liquid dimethylindium methoxide was first reported by Coates and co-workers [19] in 1956 and later shown by Weidlein and co-workers [20] to have a trimeric $\mathrm{In}_{3} \mathrm{O}_{3}$ ring structure. In 20 two monomeric $\mathrm{Me}_{2} \mathrm{InOMe}$ units are stabilized through interaction with disiloxanediolate oxygens and coordination of the methoxy groups to yttrium [9e]. 
Figure 8. Molecular structure of $\left[\left\{\left(\mathrm{Ph}_{2} \mathrm{SiO}\right)_{2} \mathrm{O}\right\}_{2}\left\{\mathrm{InMe}_{2}(\mathrm{OMe})\right\}_{2} \mathrm{InMe}_{2}\right] \mathrm{Y}(\mathbf{2 0})[9 \mathrm{e}]$

For a first study of a reaction between an "inorganic metallocene"-type lanthanide bis(disiloxanediolate) and a Group 13 metal trialkyl we chose the praseodymium complex $\left[\left\{\left(\mathrm{Ph}_{2} \mathrm{SiO}\right)_{2} \mathrm{O}\right\}_{2}\{\mathrm{Li}(\mathrm{DME})\}_{2}\right] \mathrm{PrCl}(\mathrm{DME})(\mathbf{5})$ as a typical representative of this series $[9 \mathrm{~g}]$. Treatment of this starting material with trimethylindium in a THF/toluene solvent mixture resulted in a colorless reaction mixture from which colorless crystals could be isolated. The compound is virtually insoluble in hydrocarbon solvents and diethyl ether, but well-formed single-crystals suitable for X-ray diffraction could be grown from a concentrated solution in THF. The crystal structure determination revealed the formation of an unexpected anionic complex as illustrated in Scheme 15. 


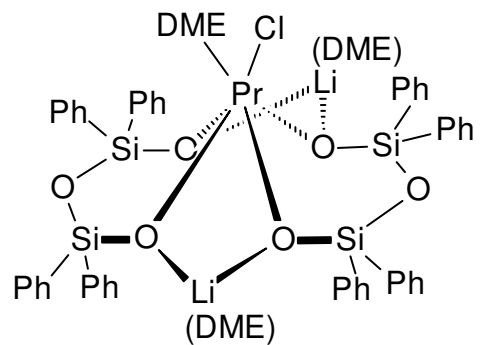

12

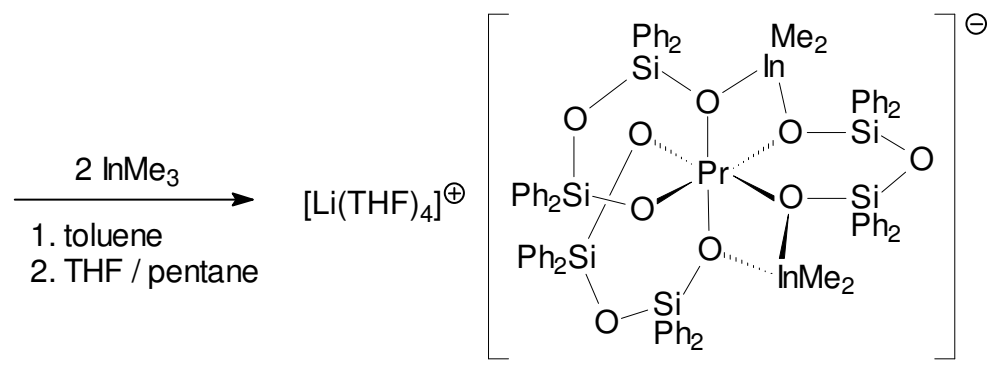

21

\section{Scheme 15}

According to the X-ray diffraction study (Fig. 9), the product obtained from treatment of 12 with 2 equivalents of $\mathrm{InMe}_{3}$ is the ionic complex [ $\left.\mathrm{Li}(\mathrm{THF})_{4}\right]\left[\mathrm{Pr}\left\{\mathrm{O}\left(\mathrm{SiPh}_{2} \mathrm{OInMe} \mathrm{I}_{2} \mathrm{O}-\right.\right.\right.$ $\left.\left.\left.\mathrm{SiPh}_{2} \mathrm{OSiPh}_{2} \mathrm{O}\right)_{2}\right\}\right]$ (21) [9g]. In the course of the reaction, not only two $\mathrm{Li}(\mathrm{DME})$ units were replaced by $\mathrm{InMe}_{2}$ moieties, but an extensive ligand rearrangement was encountered as well. While in the starting material 12 two lithium disiloxanediolate ligands are coordinated to the central praseodymium, the anion in $\mathbf{2 1}$ formally comprises three disiloxanediolate dianions. The coordination number around $\mathrm{Pr}^{3+}$ in compound $\mathbf{1 2}$ is 7 with the central praseodymium being coordinated to the tetradentate $\mathrm{Si}_{4} \mathrm{O}_{6} \mathrm{Li}_{2}$ inorganic ring, a chelating DME ligand and a chlorine. The replacement of Li(DME) fragments by $\mathrm{InMe}_{2}$ units leads to complete disruption of the metallacrown ring and formation of a formally tetraanionic $\left[\mathrm{O}\left(\mathrm{SiPh}_{2} \mathrm{OInMe}_{2} \mathrm{OSiPh}_{2} \mathrm{OSiPh}_{2} \mathrm{O}\right)_{2}\right]^{4-}$ 17-membered inorganic chain ligand wrapped around the central praseodymium as a hexadentate ligand. The negative charge of the resulting anion is compensated by a $\left[\mathrm{Li}(\mathrm{THF})_{4}\right]^{+}$cation $[9 \mathrm{~g}]$. 


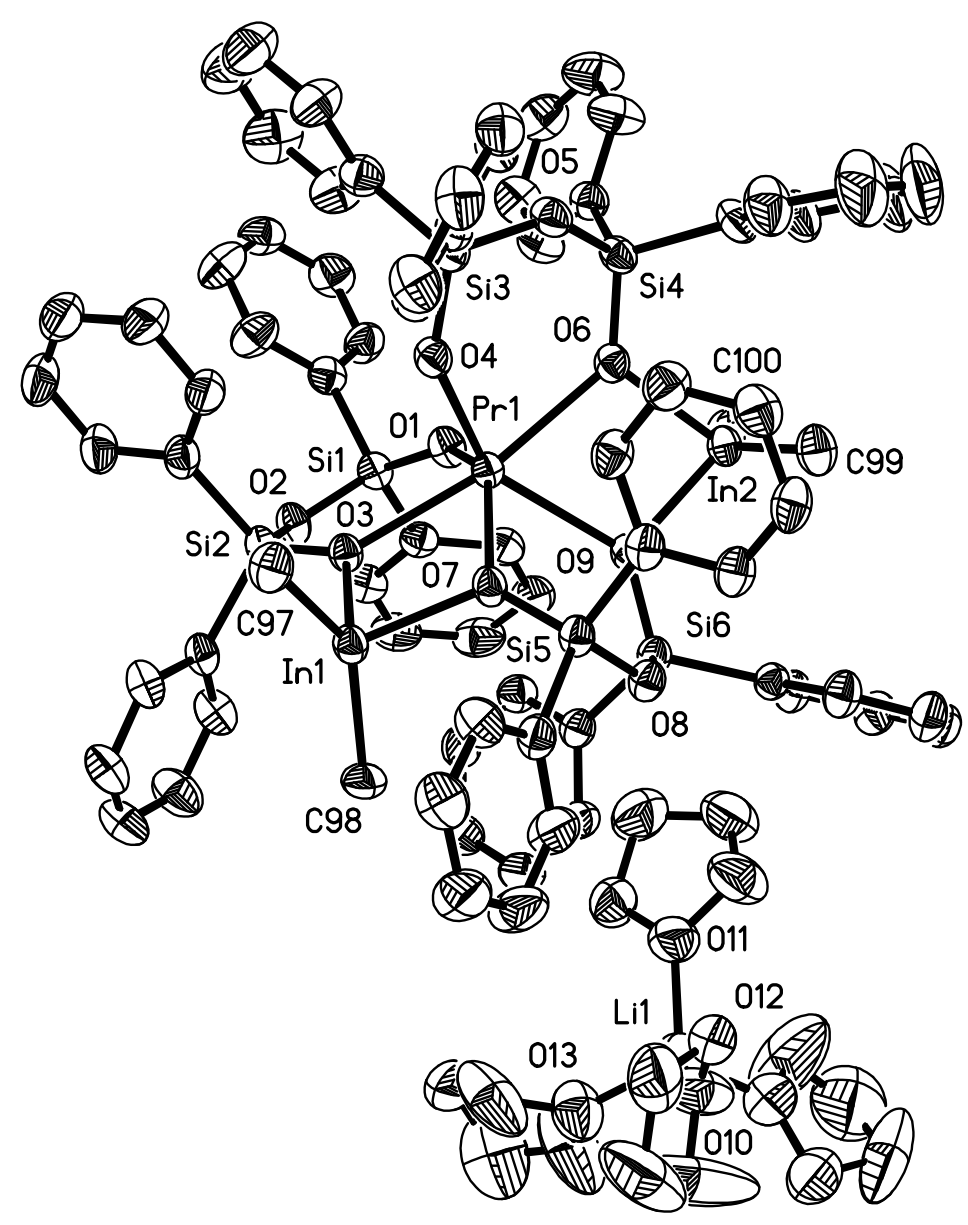

Figure 9. Molecular structure of $\left[\mathrm{Li}(\mathrm{THF})_{4}\right]\left[\mathrm{Pr}\left\{\mathrm{O}\left(\mathrm{SiPh}_{2} \mathrm{OInMe}_{2} \mathrm{OSiPh}_{2} \mathrm{OSiPh}_{2} \mathrm{O}\right)_{2}\right\}\right](\mathbf{2 1})$ $[9 \mathrm{~g}]$

In order to perhaps achieve a ring-enlargement reaction with a lanthanide bis(disiloxanediolate) derivative we studied the reaction of 15 with diphenylsilanediol, $\mathrm{Ph}_{2} \mathrm{Si}(\mathrm{OH})_{2}$ (2) [9a,b]. In fact, ring-enlargement did occur, but in a rather unexpected way. Treatment of 15 with two equivalents of $\mathbf{2}$ resulted in the formation of a colorless crystalline solid after recrystallization from acetonitrile. Spectroscopic data and an X-ray diffraction analysis revealed this material to be the acetonitrile solvate of the dilithium

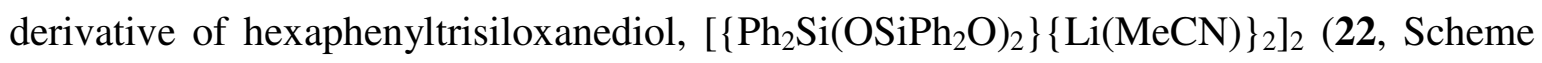


16). With 59\% the isolated yield of $\mathbf{2 2}$ was quite high, but the fate of the Gd in the starting material 15 remains unclear.

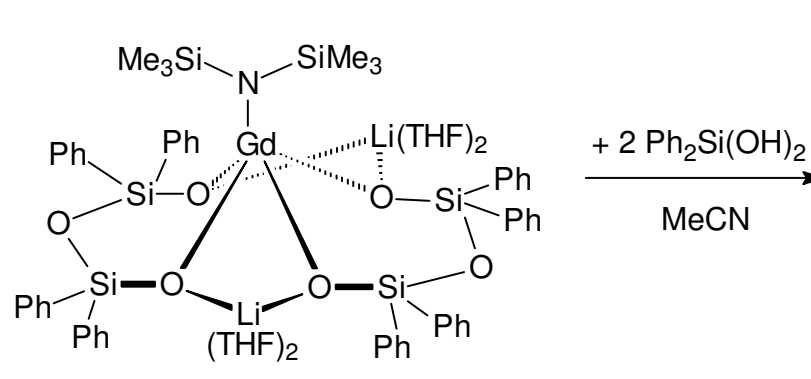

15

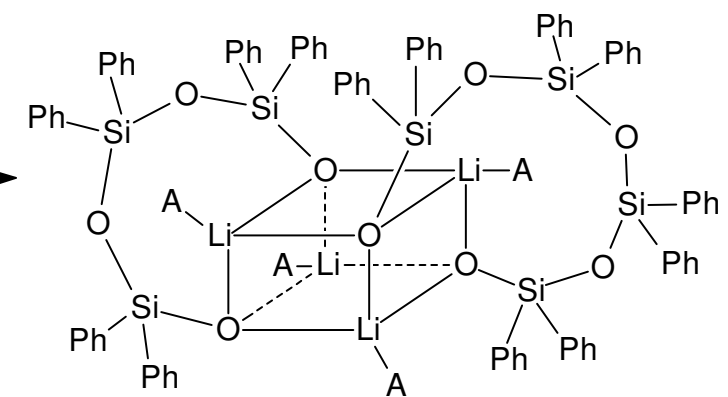

22, $A=\mathrm{MeCN}$

\section{Scheme 16}

The product $\mathbf{2 2}$ is self-assembled in the solid state in the form of a heterocubanetype dimer. The molecular structure consists of a $\mathrm{Li}_{4} \mathrm{O}_{4}$ heterocubane in which one acetonitrile ligand is coordinated to each lithium ion. The two hexaphenyltrisiloxanediolate ligands are arranged in a perpendicular fashion with respect to each other. The reaction leading to $\mathbf{2 2}$ is of interest as a deliberate way of achieving the ring-enlargement $\left[\left(\mathrm{Ph}_{2} \mathrm{SiO}\right)_{2} \mathrm{O}\right]^{2-} \rightarrow\left[\mathrm{Ph}_{2} \mathrm{Si}\left(\mathrm{OSiPh}_{2} \mathrm{O}\right)_{2}\right]^{2-}$ starting from a tetraphenyldisiloxanediolate and a monosilicon building block. In addition, the dilithium derivative $\mathbf{2 2}$ may well serve as a useful reagent for the preparation of other metal hexaphenyltrisiloxanediolates [9a,b].

\section{b) Lanthanide(III) tris(disiloxanediolates)}

Homoleptic lanthanide(III) tris(disiloxanediolates are quite rare. In the case of trivalent europium as central ion a homoleptic complex was obtained according the synthetic route outlined in Scheme 17 [9a,b]. 


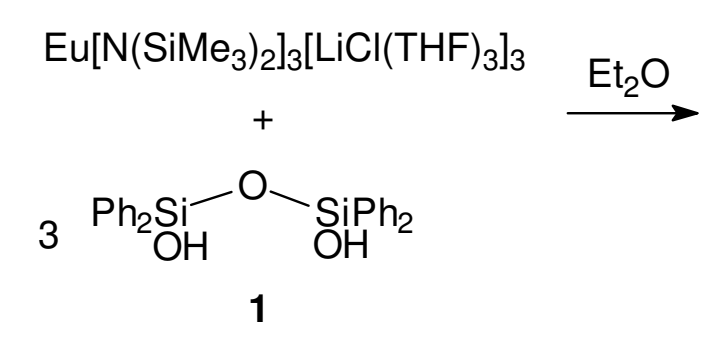
and is thus dicoordinate $[9 \mathrm{a}, \mathrm{b}]$.

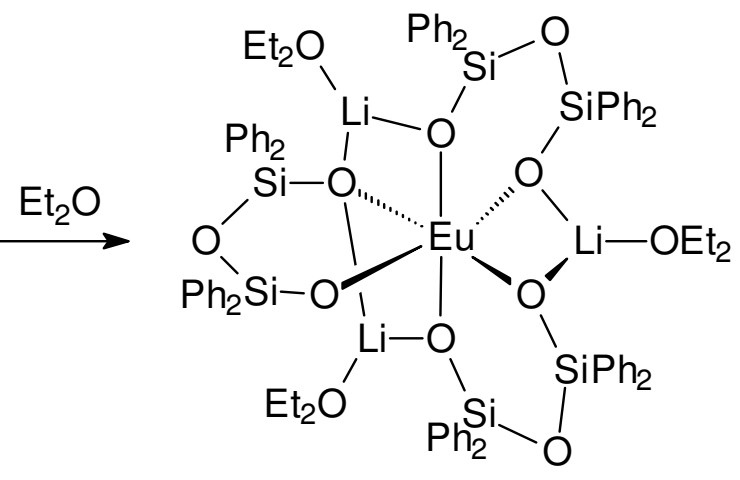

23

\section{Scheme 17}

The X-ray structural analysis of $\mathbf{2 3}$ revealed the presence of a heterobimetallic metallasiloxane, in which the $\mathrm{Eu}^{3+}$ ion is surrounded by three mono-anionic chelating $\left(\mathrm{Et}_{2} \mathrm{O}\right) \mathrm{Li}\left[\left(\mathrm{Ph}_{2} \mathrm{SiO}\right)_{2} \mathrm{O}\right]^{-}$units. Thus the molecule comprises three inorganic $\mathrm{EuSi}_{2} \mathrm{O}_{3}$ heterocyclic ring systems. The lithium ions are only tricoordinate with one diethylether ligand completing the coordination sphere around each Li. Four oxygen atoms are coordinated to one $\mathrm{Li}$ (tricoordination around $\mathrm{O}$ ) while one oxygen is engaged in two Li-O bonds (tetracoordination around $\mathrm{O}$ ). The remaining oxygen is not bonded to lithium at all

While most reactions of tetraphenyldisiloxanediol with the lanthanide silylamide reagents as described above proceeded in a clear and straightforward manner, a completely different picture was seen when anhydrous lanthanide trihalides were treated with $\mathrm{Ph}_{2} \mathrm{Si}(\mathrm{OLi}) \mathrm{OSiPh}_{2}(\mathrm{OLi})(4)$ [9b]. Some products resulting from these reactions still remain to be fully characterized, but it appears that they are all different from that shown in Scheme 17. An interesting example in which retention of lithium halide lead to a selfassembled polymeric structure is the product obtained from the reaction of anhydrous $\mathrm{NdBr}_{3}$ with three equivalents of $\mathbf{4}$ in THF solution according to Scheme 18. Extraction of the crude product with diethylether afforded the heterobimetallic neodymium disiloxanediolate $\mathbf{2 4}$ as a blue crystalline solid [9b]. 
3

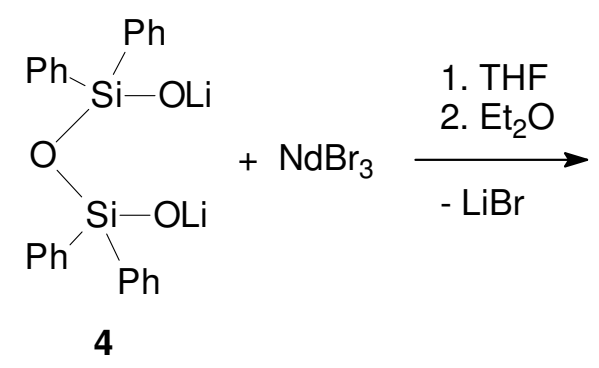

According to the X-ray analysis the neodymium complex 24 contains a central core which is closely related but not identical with that of the monomeric europium derivative 23. Three formally monoanionic lithium disiloxanediolate ligands are coordinated to $\mathrm{Nd}$ and the coordination sphere of two lithium ions is completed by an additional THF ligand. In contrast to the molecular structure of $\mathbf{2 3}$ there are four tricoordinate disiloxanediolate oxygen atoms while two are tetracoordinate. In $\mathbf{2 4}$ a polymeric superstructure results from retention of lithium bromide, which connects these monomeric units to give a linear chain polymer [9b].

\subsection{Cerium(IV) siloxanediolates}

Due to their high oxidation potential cerium(IV) compounds are widely used in various areas of chemistry and technology. Important fields of application include organic synthesis [21], bioinorganic chemistry [22], materials science [23] and industrial catalysis (automotive three-way catalysts, oxygen storage etc.) [24]. Thus there is a constant demand for new, well-defined cerium(IV) species. Cerium(IV) alkoxides form a wellinvestigated class of compounds which are of interest as precursors for the MOCVD 
production of thin $\mathrm{CeO}_{2}$ layers [25]. In sharp contrast, information about the homologous cerium(IV) siloxides comprising Ce-O-Si bonds is very scarce. $\mathrm{Ce}\left(\mathrm{OSiPh}_{3}\right)_{4}(\mathrm{DME})_{x}(0.5<$ $x<1$ ) [26] and a cerium(IV) metallasilsesquioxane complex (cf. Section 2.2) [27] are the only fully characterized compounds of this type. In the course of our investigations two unprecedented examples of cerium(IV) disiloxanediolates have been synthesized and structurally characterized [9c].

As a suitable cerium(IV) precursor the readily available alkoxide nitrate complex $\left({ }^{\mathrm{t}} \mathrm{BuO}\right)_{3} \mathrm{Ce}\left(\mathrm{NO}_{3}\right)(\mathrm{THF})_{2}$ (25) was chosen [28]. Bright yellow 25 was easily made by allowing ceric ammonium nitrate, $\left(\mathrm{NH}_{4}\right)_{2}\left[\mathrm{Ce}\left(\mathrm{NO}_{3}\right)_{6}\right](=\mathrm{CAN})$, to react with $\mathrm{NaO}^{t} \mathrm{Bu}$ in a 1:5 molar ratio. In a first experiment, 25 was treated with $\left(\mathrm{Ph}_{2} \mathrm{SiOK}\right)_{2} \mathrm{O}(\mathbf{2 6}$, made in situ by deprotonation of 1 with $\left.\mathrm{KN}\left(\mathrm{SiMe}_{3}\right)_{2}\right)$ in a molar ratio of 1:2 according to Scheme 19 . From this reaction the novel heterobimetallic potassium/cerium(IV) disiloxanediolate complex $\left[\left\{\left(\mathrm{Ph}_{2} \mathrm{SiO}\right)_{2} \mathrm{O}\right\}\left\{\mathrm{K}(\mathrm{THF})_{2}\right\}\right]_{2} \mathrm{Ce}\left(\mathrm{O}^{\mathrm{t} B u}\right)_{2}(27)$ was isolated in the form of yellow, block-shaped crystals in $81 \%$ yield. (Scheme 19) [9c].

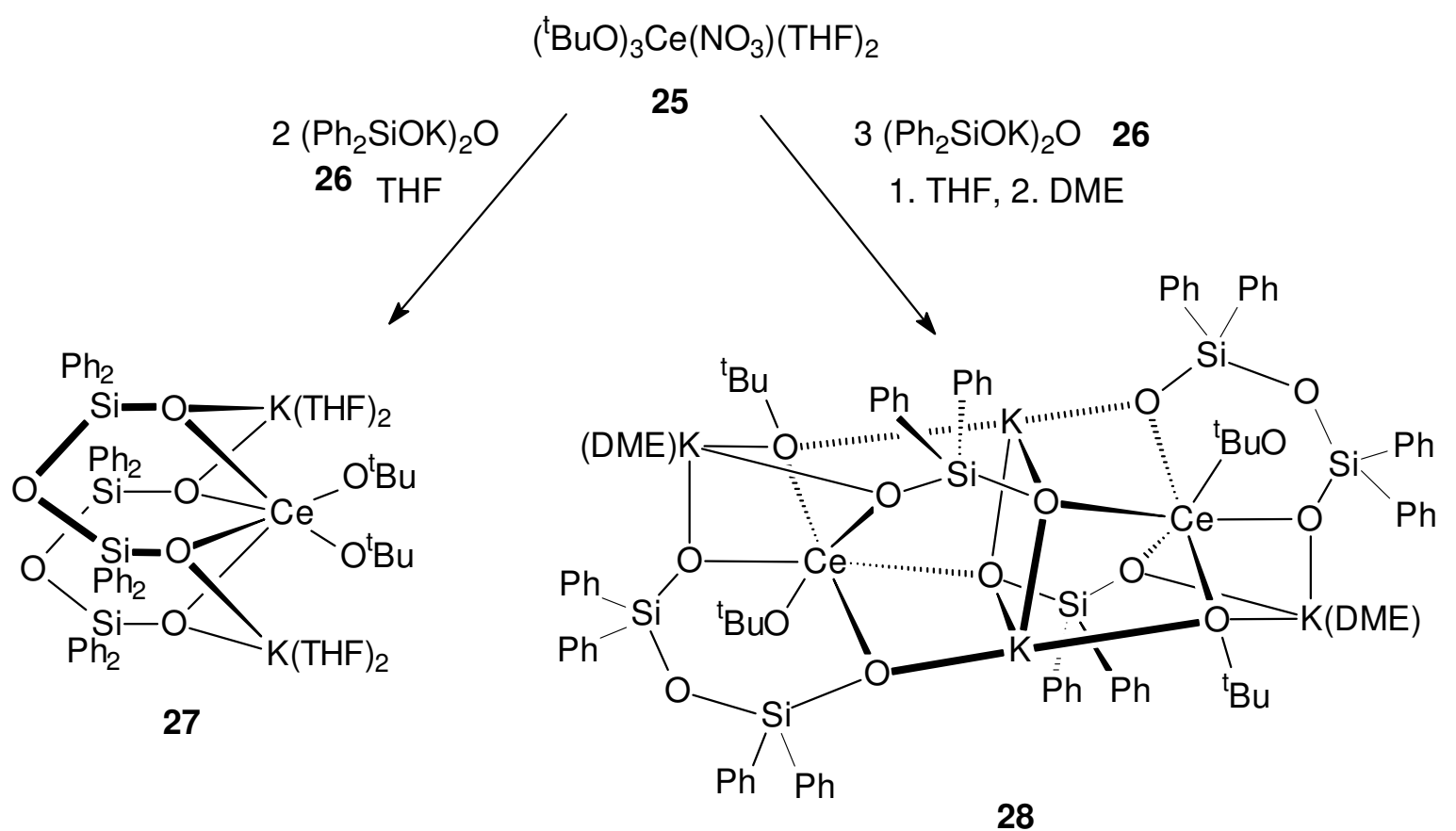

Scheme 19 
In the molecule of $\mathbf{2 7}$ two potassium disiloxanediolate ligands are coordinated to cerium(IV) in a slightly bent coordination geometry. Two tert-butoxide ligands remain as functionalizable groups coordinated to $\mathrm{Ce}$. The central cerium is in a distorted octahedral coordination environment. One phenyl ring of each disiloxanediolate ligand is engaged in an intramolecular $\eta^{1}-\pi$-coordination to potassium $(\mathrm{K}(1)-\mathrm{C}(22) 3.395(4) \AA)$. The same reaction carried out in a molar ratio of 1:3 took an entirely different course. In this case a light yellow compound could be isolated in high yield ( $c a .70 \%$ ), which was shown by Xray crystallography to be the novel heterobinuclear potassium/cerium(IV) disiloxanediolate cluster $\left[\left\{\left(\mathrm{Ph}_{2} \mathrm{SiO}\right)_{2} \mathrm{O}\right\}_{2}\left\{(\mathrm{DME}) \mathrm{KO}^{\mathrm{t}} \mathrm{Bu}\right\}\left\{\left(\mathrm{Ph}_{2} \mathrm{SiO}_{2}\right) \mathrm{K}\right\} \mathrm{Ce}\right]_{2}$ (28). The X-ray study revealed that in $\mathbf{2 8}$ not only the expected dianions of 1,1,3,3-tetraphenyl-1,3-disiloxanediol act as ligands, but also the dianions of diphenyl-1,1-silanediol, which originate from cleavage of the disiloxanediolate (Fig. 10). Such transformations are not uncommon in the chemistry of silanediolates, disiloxanediolates, and trisiloxanediolates [6,7,9a,9b] In the unprecedented centrosymmetric cluster molecule 28 a planar $\mathrm{K}_{2} \mathrm{O}_{2}$ ring forms the central structural unit. The central cerium atoms in $\mathbf{2 8}$ are in a distorted octahedral coordination environment. Two disiloxanediolate dianions act as chelating ligands towards each Ce(IV) and simultaneously bridge two potassium ions with the cerium. An unusual $\mu_{3}, \mu_{2}$-bridging coordination mode was found for the dianionic diphenyl-1,1-silanediolate ligands. One oxygen from each of the two $\mathrm{Ph}_{2} \mathrm{SiO}_{2}{ }^{2-}$ ligands bridges one $\mathrm{Ce}$ and two potassium ions, while the other oxygen forms a $\mu^{2}$-bridge to $\mathrm{Ce}$ and $\mathrm{K}$. The overall coordination geometry around each cerium is slightly distorted octahedral. Four tert-butoxide groups originating from precursor $\mathbf{2 5}$ are also present in the molecular structure of $\mathbf{2 8}$, two of them bridging $\left(\mathrm{K}^{+}, \mathrm{K}^{+}\right)$and the other two terminally bonded to cerium. Given the high isolated yield it is clear that despite its highly unusual structure compound $\mathbf{2 8}$ is the main product of the reaction of $\mathbf{2 5}$ with 3 equivalents of $\mathbf{2 6}$. The coordinative unsaturation of the potassium 
ions (coordination numbers 4 and 5 , resp.) is relieved by $\eta^{1}$ - and $\eta^{2}-\pi$-interactions with neighboring phenyl substituents. The respective $\mathrm{K} \cdots \mathrm{C}$ distances are in the range of 3.173 $3.527(4) \AA$. The fact that the nitrate group of the starting material was completely eliminated demonstrates the usefulness of $\mathbf{2 5}$ as a precursor for the synthesis of novel cerium(IV) siloxide species. Due to the remaining two ${ }^{\mathrm{t}} \mathrm{BuO}$ ligands compound 27 also represents a potentially useful synthon for other tetravalent cerium species [9c].

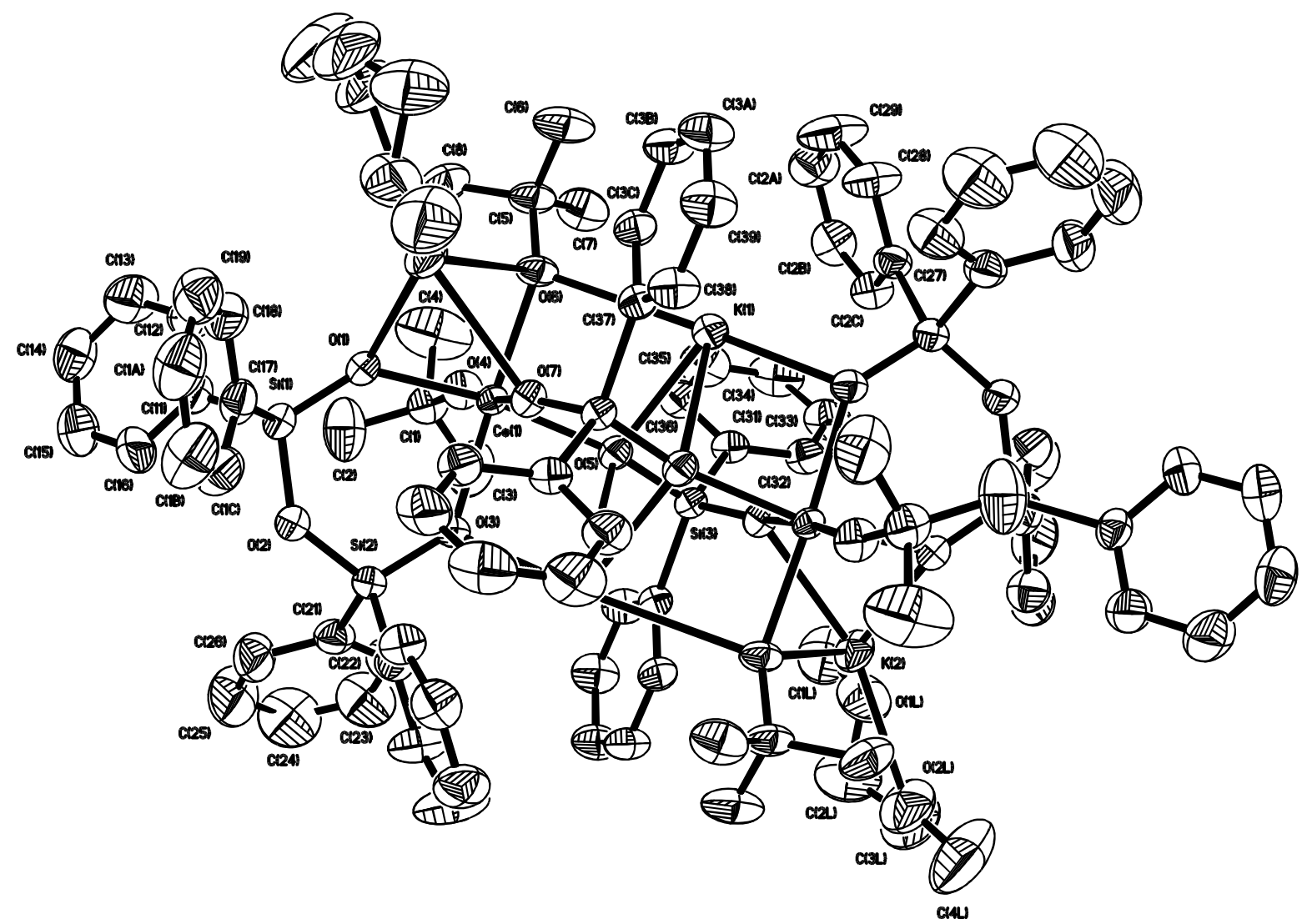

Figure 10. Molecular structure of $\left[\left\{\left(\mathrm{Ph}_{2} \mathrm{SiO}\right)_{2} \mathrm{O}\right\}_{2}\left\{(\mathrm{DME}) \mathrm{KO}^{\mathrm{t}} \mathrm{Bu}\right\}\left\{\left(\mathrm{Ph}_{2} \mathrm{SiO}_{2}\right) \mathrm{K}\right\} \mathrm{Ce}\right]_{2}(\mathbf{2 8})$

\section{Metallasilsesquioxanes of the lanthanides}

\subsection{Lanthanide(III) metallasilsesquioxanes}

Polyhedral oligosilsesquioxanes of the general formula $\left(\mathrm{RSiO}_{1.5}\right)_{\mathrm{n}}$ form an interesting and unusual class of organosilicon compounds which currently have a strong impact on both catalysis research [29,30] and materials science [31]. In accordance with 
several unique properties, the polyhedral silsesquioxanes have been termed the "smallest particles of silica possible" [32] or "small soluble chunks of silica" [33]. With respect to catalysis research the chemistry of metallasilsesquioxanes also receives considerable current interest [29,30,33,34]. Incompletely condensed silsesquioxanes such as (c$\left.\mathrm{C}_{6} \mathrm{H}_{11}\right)_{7} \mathrm{Si}_{7} \mathrm{O}_{9}(\mathrm{OH})_{3}(\mathbf{2 9}$, Scheme 20) share far-reaching structural similarities with $\beta$ tridymite and $\beta$-cristobalite and are thus suitable models for the silanol sites on silica surfaces.[29,30,34-37]

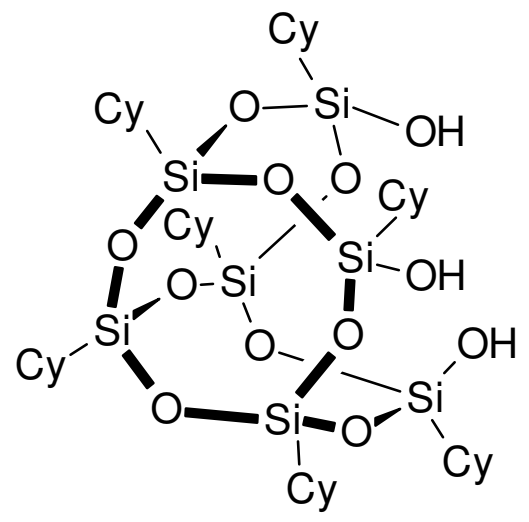

\section{9}

Scheme 20

Metal complexes derived from $\mathbf{2 9}$ are therefore commonly regarded as "realistic" models for industrially important metal catalysts immobilized on silica surfaces.[29,30,35] It is mainly the latter aspect, i.e. the mimicking of heterogeneous metal catalysts with the use of soluble compounds, that currently attracts various research groups to the chemistry of incompletely condensed silsesquioxanes. Examples of silica-supported species which have been successfully modeled with the use of silsesquioxanes are e.g. Phillips- and Ziegler-Natta-type olefin polymerization catalysts as well as silica-supported perfluoroborato co-catalysts (Scheme 21) [29d,38]. 

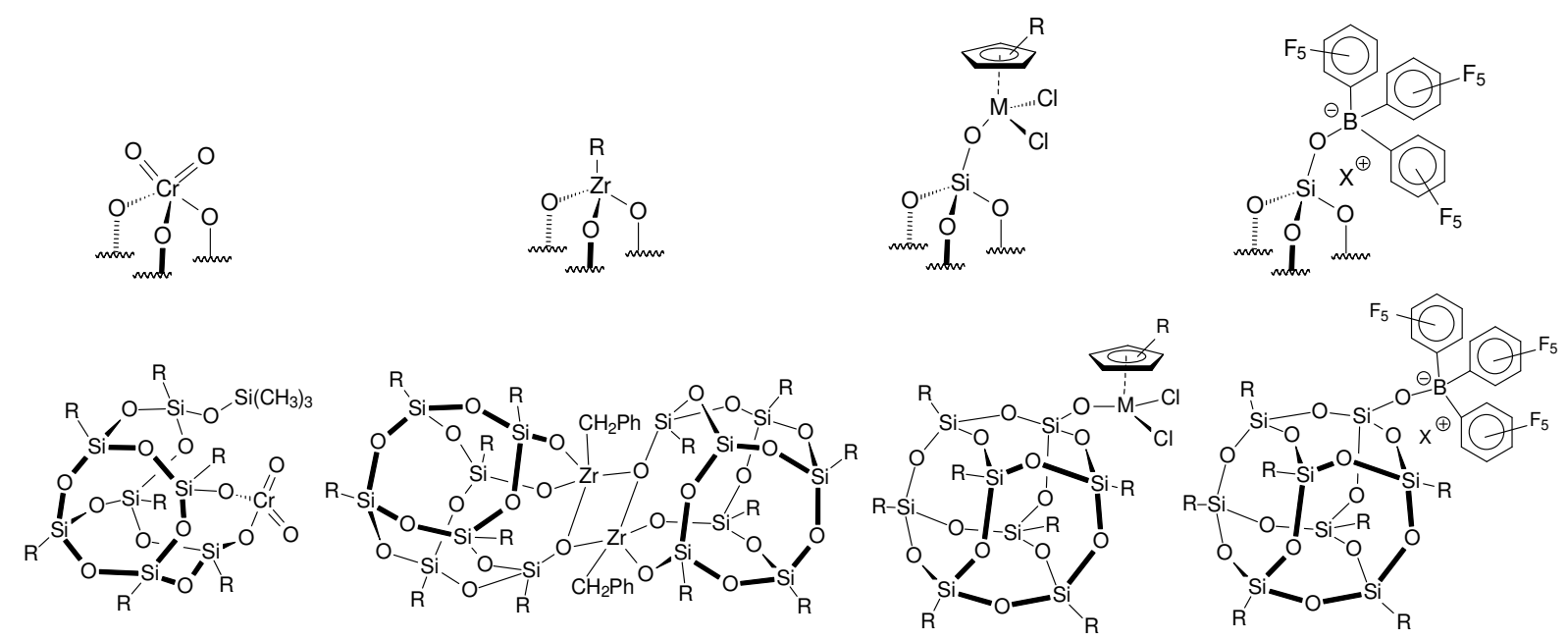

Scheme 21

The "Periodic Table of Metallasilsesquioxanes" [29b] already covers numerous metallic elements ranging from alkali metals through early and late transition metals to the lanthanide elements [29]. Information on well-characterized lanthanide silsesquioxane derivatives is still quite limited. Metallasilsesquioxanes of rare earth metals could be very important as homogeneous analogues of rare earth metal silica-supported catalysts and rare earth silicates, which are potential materials for optoelectronics [29d]. Thus this area of research is of considerable interest for several fields of chemistry including catalysis and materials science. However, investigations in the area of metallasilsesquioxanes of rare earth metals are often hampered by difficulties with crystallization and characterization of these compounds. The first metallasilsesquioxanes incorporating lanthanide elements have been described in 1994 by Herrmann et al. [39]. These materials were obtained by treatment of $\mathbf{2 9}$ with the tris(silylamides) $\mathrm{Ln}\left[\mathrm{N}\left(\mathrm{SiMe}_{3}\right)_{2}\right]_{3}$ of $\mathrm{Y}$ and $\mathrm{Nd}$. Due to their very high solubility no structural characterization of the initially formed products was possible. However, with the use of triphenylphosphine oxide as supporting ligand X-ray quality single crystals could be obtained, and a dimeric structure was established for the $\mathrm{Y}$ and $\mathrm{Nd}$ silesesquioxane 
complexes. Aspinall et al. reported the synthesis of a series of lanthanide silsesquioxanes resulting from reactions of 29 with lanthanide tris(silylamides) $\mathrm{Ln}\left[\mathrm{N}\left(\mathrm{SiMe}_{3}\right)_{2}\right]_{3}(\mathrm{Ln}=\mathrm{Y}$, $\mathrm{La}, \mathrm{Pr}, \mathrm{Eu}, \mathrm{Yb}$ ) [40]. However, single crystals of these materials suitable for X-ray diffraction could not be obtained. The somewhat complicated situation is illustrated in Scheme 22. The lanthanide tris(silylamides) reacted with $2 / 3$ equivalents of the trisilanol $\mathbf{2 9}$ in THF to give the lanthanide silsesquioxanes $\mathbf{3 0}$ which are dimeric in solution at $233 \mathrm{~K}$. Reaction of $\mathrm{Ln}\left[\mathrm{N}\left(\mathrm{SiMe}_{3}\right)_{2}\right]_{3}$ with 1 equivalent of 29 in $\mathrm{THF}$ resulted in complete conversion of 29 into the trisilylated compound 31, as did the reaction of $\mathrm{Ln}\left[\mathrm{N}\left(\mathrm{SiMe}_{3}\right)_{2}\right]_{3}$ with 2/3 equivalents of $\mathbf{2 9}$ in toluene [40].

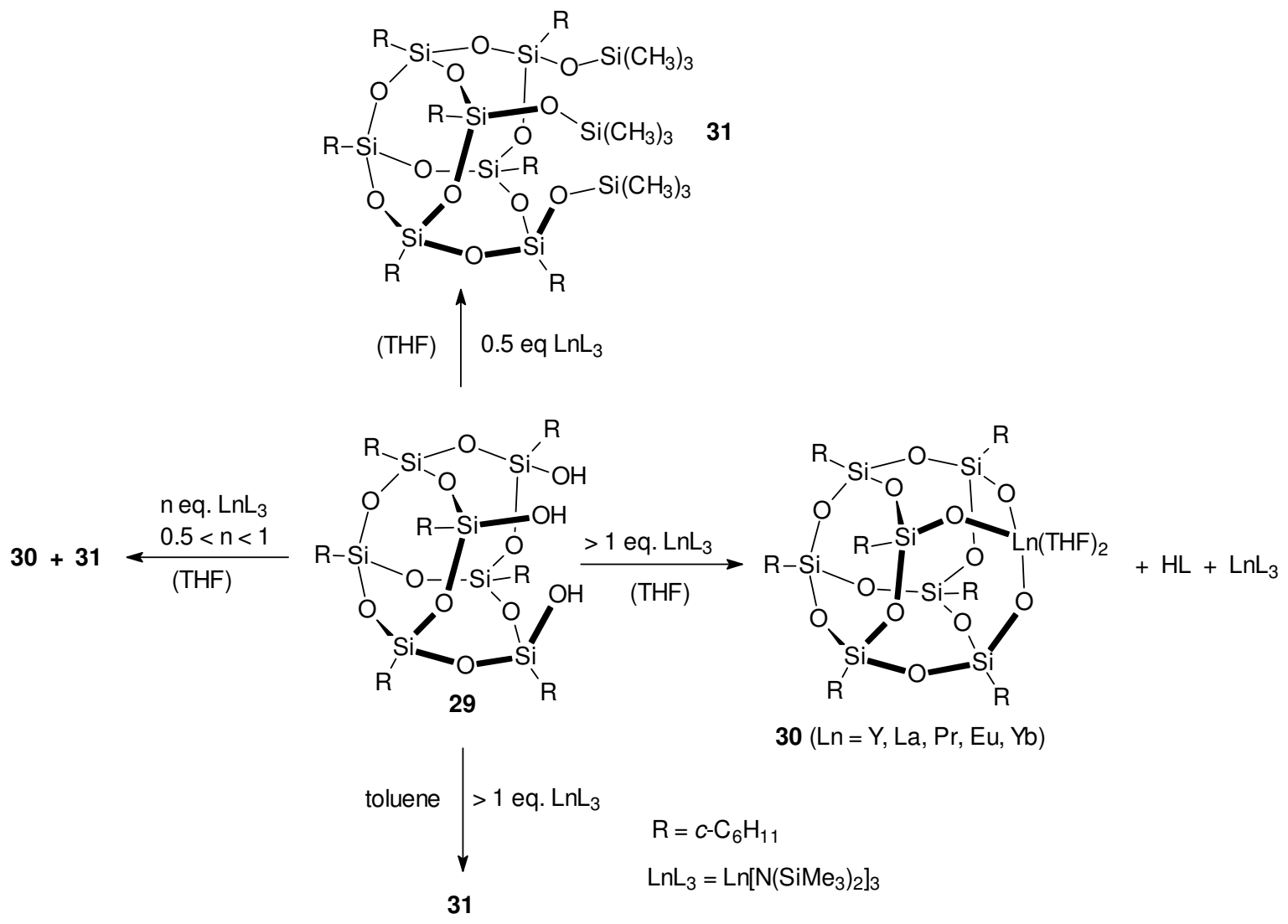

Scheme 22

Variable temperature ${ }^{13} \mathrm{C}$ NMR data of the $\mathrm{Y}$ derivative were consistent with a monomer/dimer equilibrium for compounds 30 in solution as depicted in Scheme 23 [40]. 


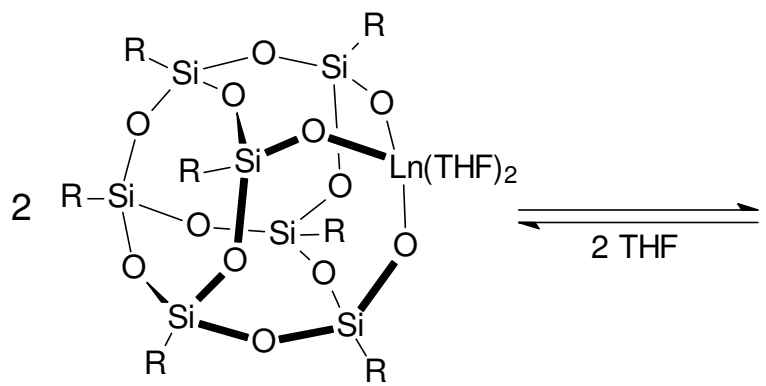

$\mathrm{R}=c-\mathrm{C}_{6} \mathrm{H}_{11}$

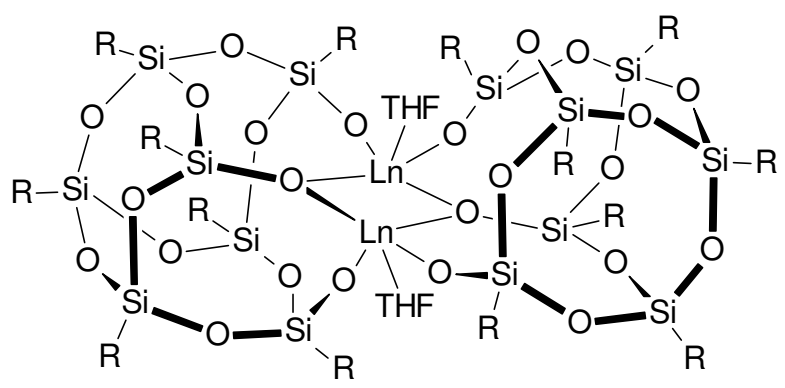

Scheme 23

The chloro-functionalized lanthanide silsesquioxane complexes $32(\mathrm{Ln}=\mathrm{Y}, \mathrm{La})$ are accessible by the reaction of $\mathbf{3 0}$ with 1 equivalent of $\mathrm{Me}_{3} \mathrm{SiCl}$ according to Scheme 24 [40].<smiles>[R][R]12O[Si]3([R])O[Si]4([R])O[Si]([R])(O1)O[Si]1([R])O[Si]([R])(O2)O[Si]([R])(O3)O[Si]([R])(O4)O1</smiles>

$\mathrm{R}=c-\mathrm{C}_{6} \mathrm{H}_{11}$

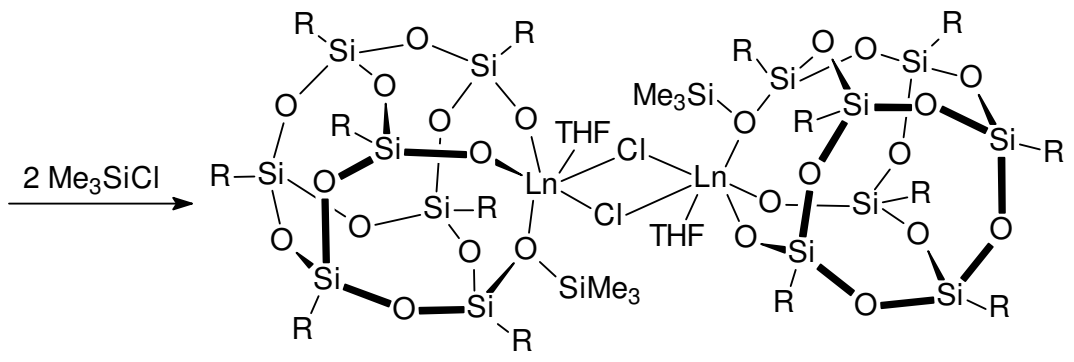

32, $\mathrm{Ln}=\mathrm{Y}, \mathrm{La}$

Scheme 24

Well-defined monomeric derivatives could be obtained by treatment of $\mathbf{3 0}(\mathrm{Ln}=\mathrm{Y}$, $\mathrm{La}, \mathrm{Yb})$ with $\left(\mathrm{Me}_{2} \mathrm{NCH}_{2} \mathrm{CH}_{2}\right)_{2} \mathrm{NMe}$ (PMDTA) in a 1:1 molar ratio in THF solution. The products $\mathrm{Cy}_{7} \mathrm{Si}_{7} \mathrm{O}_{12} \mathrm{Ln}(\mathrm{PMDTA})(33, \mathrm{Ln}=\mathrm{Y}, \mathrm{La}, \mathrm{Yb})$ are depicted in Scheme 25. In all these cases severe disorder problems prevented a structural characterization of the lanthanide silsesquioxanes by X-ray diffraction [40]. 


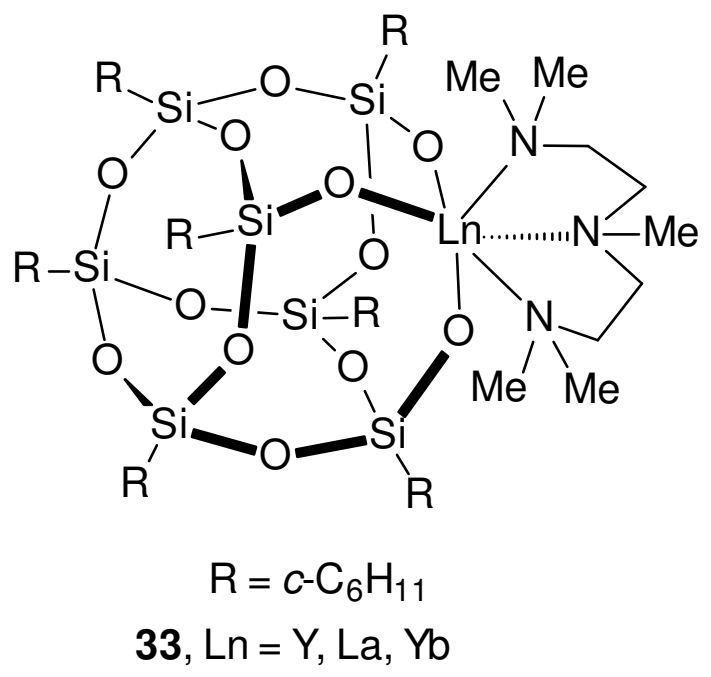

Scheme 25

The ytterbium derivative $\mathrm{Cy}_{7} \mathrm{Si}_{7} \mathrm{O}_{12} \mathrm{Yb}(\mathrm{PMDTA})(33, \mathrm{Ln}=\mathrm{Yb})$ was also obtained directly from $\mathrm{Yb}\left[\mathrm{N}\left(\mathrm{SiMe}_{3}\right)_{2}\right]_{3}$ and 29 in the presence of PMDTA [41]. Attempts to grow single crystals of $\mathrm{Cy}_{7} \mathrm{Si}_{7} \mathrm{O}_{12} \mathrm{Yb}(\mathrm{PMDTA})$ resulted in a small number of good-quality prisms, which were shown by X-ray diffraction to be the heterobimetallic $\mathrm{Li} / \mathrm{Yb}$ silsesquioxane complex $\left[\left(\mathrm{Cy}_{7} \mathrm{Si}_{7} \mathrm{O}_{12}\right)\left\{\mathrm{Cy}_{7} \mathrm{Si}_{7} \mathrm{O}_{11}\left(\mathrm{OSiMe}_{3}\right)\right\} \mathrm{YbLi}_{2}(\mathrm{THF})_{2}(\mathrm{MeCN})\right] \cdot 2.5 \mathrm{THF}$ (34). Compound 34 could be more rationally prepared by lithiation of $\mathrm{Cy}_{7} \mathrm{Si}_{7} \mathrm{O}_{9}(\mathrm{OH})_{2}\left(\mathrm{OSiMe}_{3}\right)$ (35) with ${ }^{n} \mathrm{BuLi}$ and reaction of the resulting $\mathrm{Cy}_{7} \mathrm{Si}_{7} \mathrm{O}_{9}(\mathrm{OLi})_{2}\left(\mathrm{OSiMe}_{3}\right)$ (36) with $\mathrm{Cy}_{7} \mathrm{Si}_{7} \mathrm{O}_{12} \mathrm{Yb}(\mathrm{THF})_{2}(33, \mathrm{Ln}=\mathrm{Yb})$. The yttrium analogue of $\mathbf{3 4}$ was prepared in a similar manner [41].

Arnold et al. reported the synthesis and structural characterization of an aryloxidefunctionalized samarium silsesquioxane complex [42]. Steric protection of (c$\left.\mathrm{C}_{5} \mathrm{H}_{9}\right)_{7} \mathrm{Si}_{7} \mathrm{O}_{9}(\mathrm{OH})_{3}$ by one $\mathrm{SiMe}_{2}{ }^{t} \mathrm{Bu}$ group generated a new disilanol ligand, $(c-$ $\left.\mathrm{C}_{5} \mathrm{H}_{9}\right)_{7} \mathrm{Si}_{7} \mathrm{O}_{9}(\mathrm{OH})_{2}\left(\mathrm{OSiMe}_{2}{ }^{t} \mathrm{Bu}\right)(37)$, that allows only restricted access to a co-ordinated metal. Lithiation of 37 with ${ }^{t} \mathrm{BuLi}$ afforded the stable dilithium intermediate $(c$ $\left.\mathrm{C}_{5} \mathrm{H}_{9}\right)_{7} \mathrm{Si}_{7} \mathrm{O}_{9}\left(\mathrm{OSiMe}_{2}{ }^{t} \mathrm{Bu}\right)(\mathrm{OLi})_{2}$ (38). Subsequent reaction of 38 with the homoleptic 
samarium aryloxide $\operatorname{Sm}\left(\mathrm{OC}_{6} \mathrm{H}_{3}{ }^{t} \mathrm{Bu}_{2}-2,6\right)_{3}$ according to Scheme 26 gave the novel heterobimetallic Li/Sm silsesquioxane complex 39 [42].

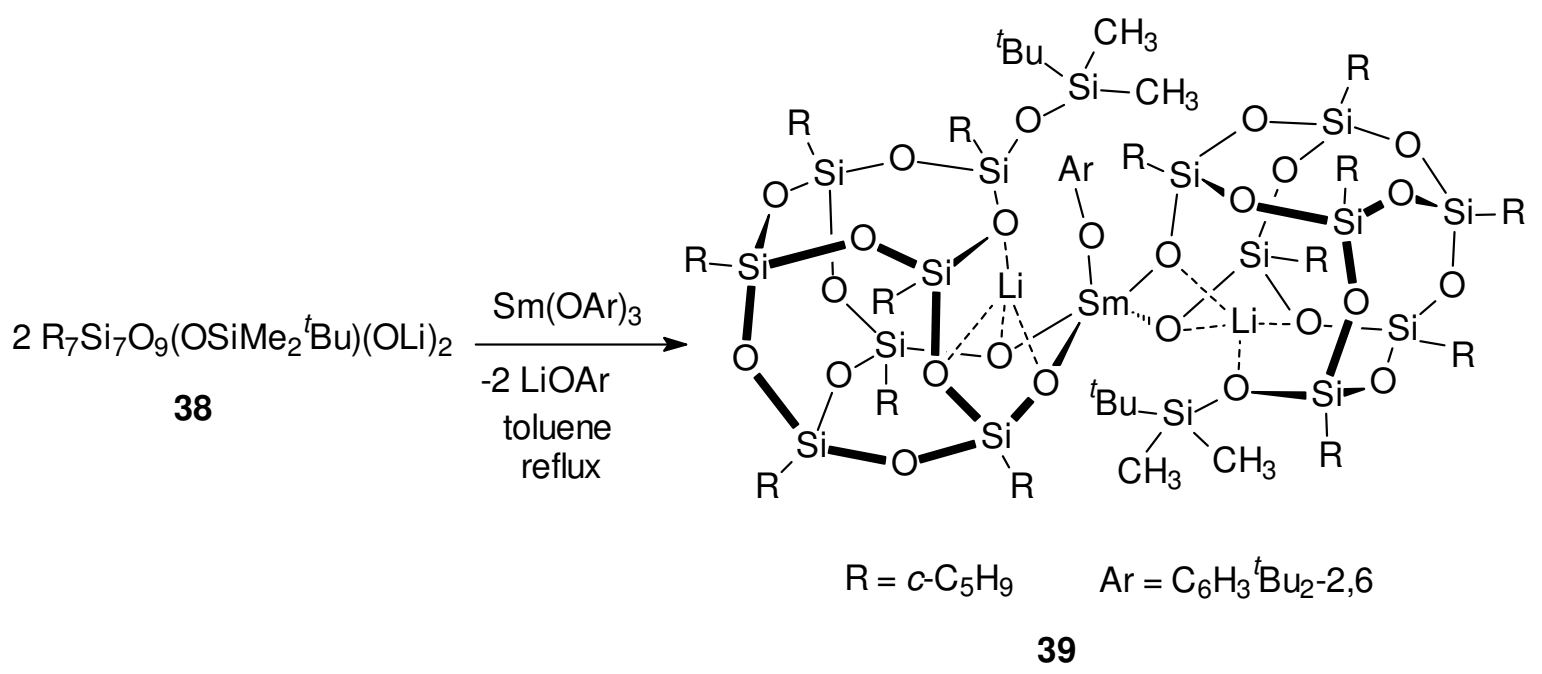

Scheme 26

Our own efforts in this field resulted in the isolation of bimetallic gadolinium and ytterbium derivatives. These novel functionalized lanthanide silsesquioxanes were obtained as outlined in Scheme 27. Trisilanol 29 was lithiated in situ using an excess of $\mathrm{LiN}\left(\mathrm{SiMe}_{3}\right)_{2}$ to give $\mathbf{4 0}$, followed by treatment of the reaction mixture with $\mathrm{LnCl}_{3}(\mathrm{THF})_{3}$ $(\mathrm{Ln}=\mathrm{Gd}, \mathrm{Yb})$ [43]. The resulting colorless crystals of $41(\mathrm{Ln}=\mathrm{Yb})$ were fully characterized by spectroscopic and analytical methods as well as an X-ray crystal structure determination. In this molecule a reactive ytterbium bis(trimethylsilyl)amide unit resides on a model silica surface formed by two lithium-linked silsesquioxane cages. Thus the compounds $41(\mathrm{Ln}=\mathrm{Gd}, \mathrm{Yb})$ represented the first example of a mono-functional lanthanide silsesquioxane which could be of interest for catalytic applications [43]. 

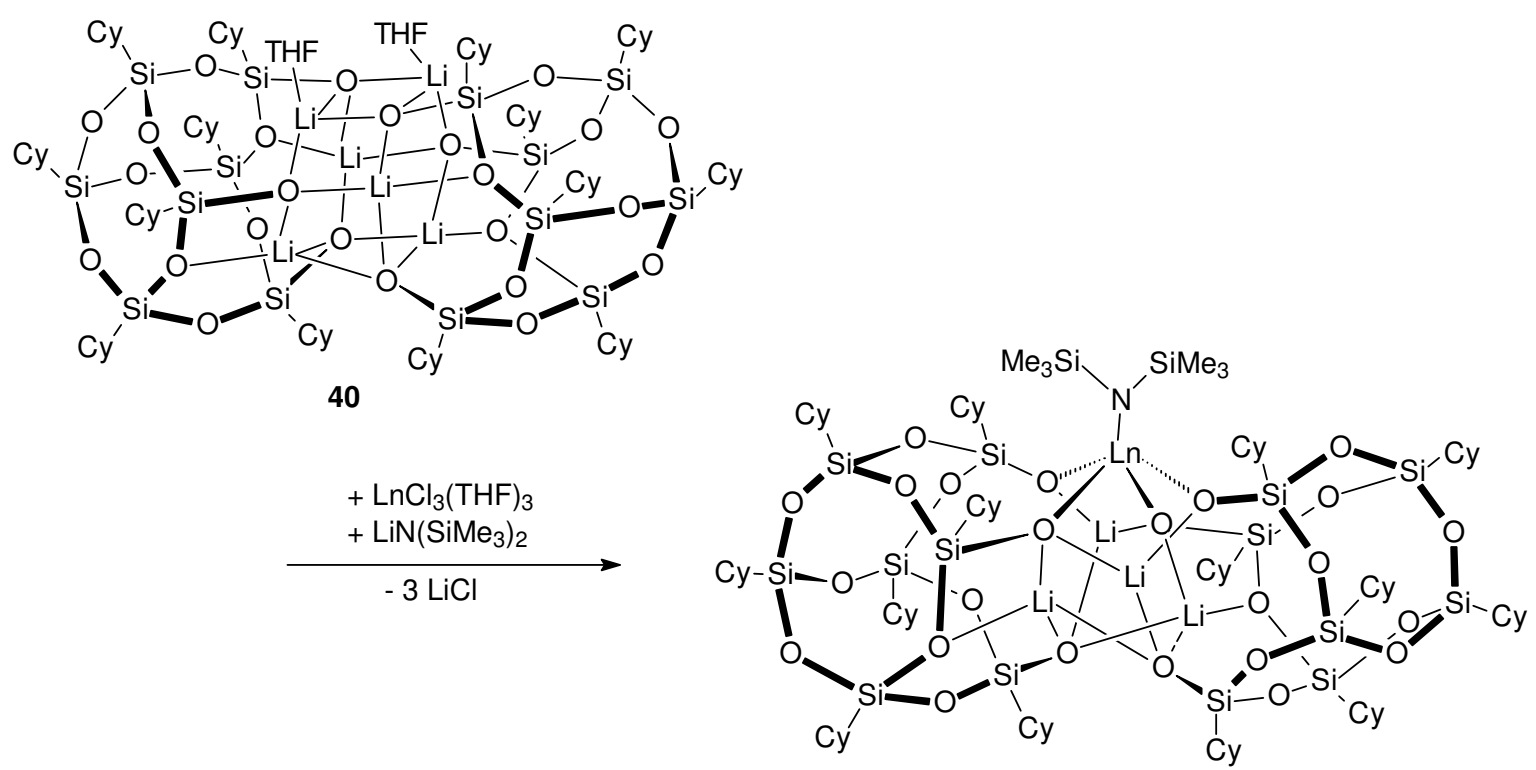

41, $\mathrm{Ln}=\mathrm{Gd}, \mathrm{Yb}$

Scheme 27

Two novel complexes of samarium- and scandium-containing silsesquioxane silanolate ligands were synthesized with the use of the closo-silsesquioxane silanolate ligand $\mathrm{Cy}_{7} \mathrm{Si}_{8} \mathrm{O}_{12} \mathrm{O}^{-}$and structurally characterized by $\mathrm{X}$-ray diffraction [44]. Yellow $\left(\mathrm{C}_{5} \mathrm{Me}_{5}\right)_{2} \mathrm{Sm}\left[\mu-\mathrm{Cy}_{7} \mathrm{Si}_{8} \mathrm{O}_{12} \mathrm{O}\right]_{2} \mathrm{Li}(\mathrm{THF})$ (42), the first organolanthanide silsesquioxane complex reported in the literature, has been obtained by treatment of the "ate"-complex $\left(\mathrm{C}_{5} \mathrm{Me}_{5}\right)_{2} \mathrm{Sm}(\mu-\mathrm{Cl})_{2} \mathrm{Li}(\mathrm{THF})_{2}$ with $\mathrm{Cy}_{7} \mathrm{Si}_{8} \mathrm{O}_{12} \mathrm{OLi}(44)$ in a molar ratio of 1:2 (Scheme 28). The starting material $\mathrm{Cy}_{7} \mathrm{Si}_{8} \mathrm{O}_{12} \mathrm{OH}(43)$ was prepared in close analogy to a published procedure [45] in two steps by treatment of $\mathbf{2 9}$ with $\mathrm{SiCl}_{4}$ in the presence of triethylamine, followed by hydrolysis of the intermediate chlorosilane $\mathrm{Cy}_{7} \mathrm{Si}_{7} \mathrm{O}_{12} \mathrm{Cl}$. Metalation of $\mathrm{Cy}_{7} \mathrm{Si}_{8} \mathrm{O}_{12} \mathrm{OH}$ with methyllithium in diethylether proceeded smoothly at room temperature to afford $\mathrm{Cy}_{7} \mathrm{Si}_{8} \mathrm{O}_{12} \mathrm{OLi}$ (44), which was used in situ for further reactions. An X-ray diffraction study revealed the presence of a heterobimetallic complex in which samarium and lithium are bridged by two silsesquioxane silanolate ligands [44].

A different synthetic approach was chosen to synthesize a related scandium silsesquioxane complex [44]. Treatment of $\left(\mathrm{C}_{5} \mathrm{Me}_{5}\right) \mathrm{Sc}(\mathrm{acac})_{2}$ [46] with the free silanol 
$\mathrm{Cy}_{7} \mathrm{Si}_{8} \mathrm{O}_{12} \mathrm{OH}(43)$ in refluxing toluene (molar ratio $1: 1$ ) resulted in elimination of pentamethylcyclopentadiene and formation of the novel binuclear scandium complex $\left[\mathrm{Sc}(\mathrm{acac})_{2}\left(\mu-\mathrm{Cy}_{7} \mathrm{Si}_{8} \mathrm{O}_{12} \mathrm{O}\right)\right]_{2}$ (45) (Scheme 28). Colorless single-crystals of 45 suitable for X-ray diffraction were obtained by fractional crystallization from pentane. The crystal structure consists of dimeric molecules in which two $\mathrm{Sc}(\mathrm{acac})_{2}$ units are symmetrically bridged by the mono-anionic silsesquioxane silanolate ligands. Compound $\mathbf{4 5}$ represented the first example of a scandium complex containing silsesquioxane derivatives as ligands. The only closely related compound is the trinuclear scandium disiloxanediolate complex $\left[\left(\mathrm{Ph}_{2} \mathrm{Si}_{2} \mathrm{O}\right)_{2} \mathrm{O}\right]_{2} \mathrm{Sc}_{3}(\mathrm{acac})_{5}$ which has been prepared in a similar manner by treatment of $\left(\mathrm{C}_{5} \mathrm{Me}_{5}\right) \mathrm{Sc}(\mathrm{acac})_{2}$ with 1,1,3,3-tetraphenyldisiloxanediol [9b].

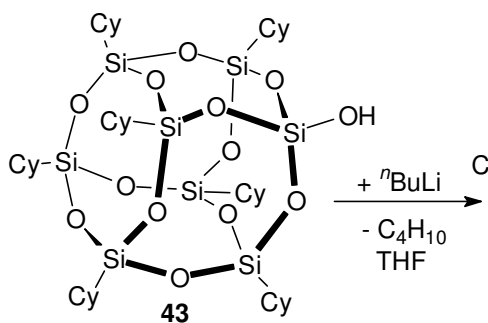

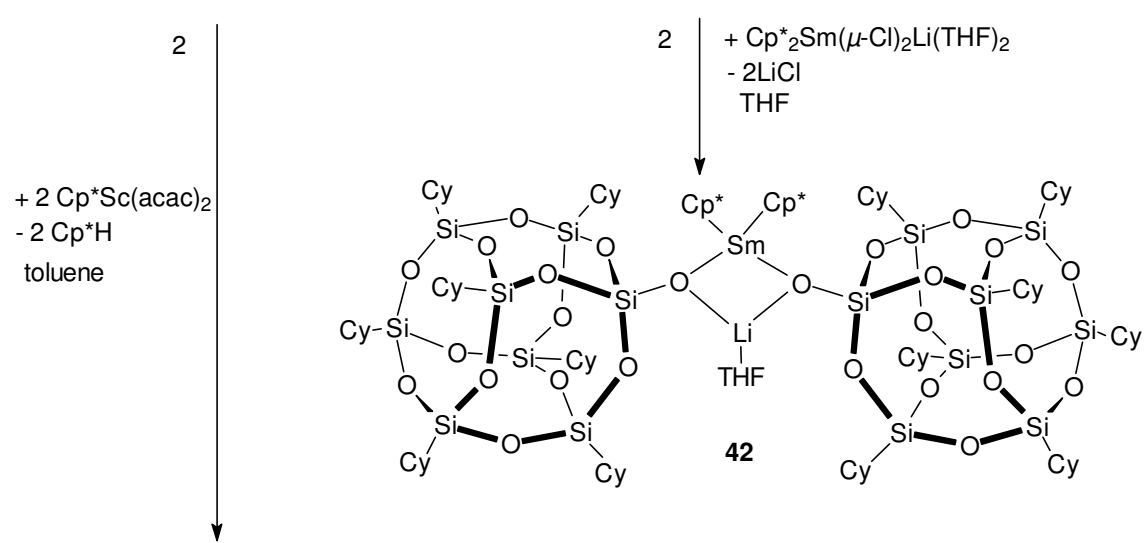

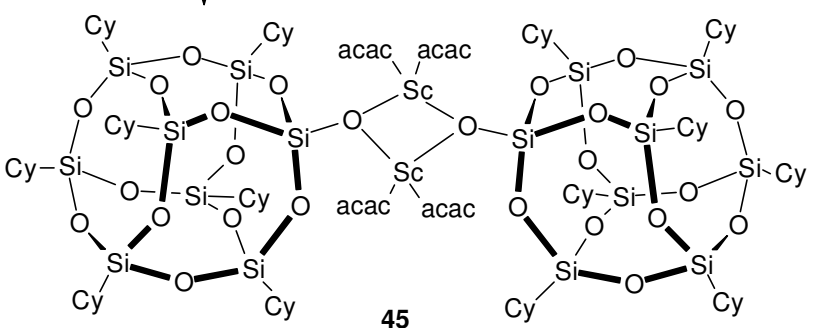

$\mathrm{Cp}^{*}=$ pentamethylcyclopentadienyl

Scheme 28 
Very recently, a tetrameric neodymium-silsesquioxane complex (46) was prepared according to Scheme 29 and structurally characterized by single-crystal X-ray diffraction. The four $\mathrm{Nd}$-silsesquioxane cages of $\mathbf{4 6}$ are linked by multiple $\mathrm{Nd}-\mathrm{O}-\mathrm{Nd}$ and $\mathrm{Nd}-\mathrm{Cl}-\mathrm{Nd}$ units. A preliminary study showed that the complex is active for highly cis-1,4 polymerization of isoprene (92\% selectivity) in the presence of $\mathrm{AlEt}_{3}$ and $\mathrm{Me}_{3} \mathrm{SiCl}$ [47].

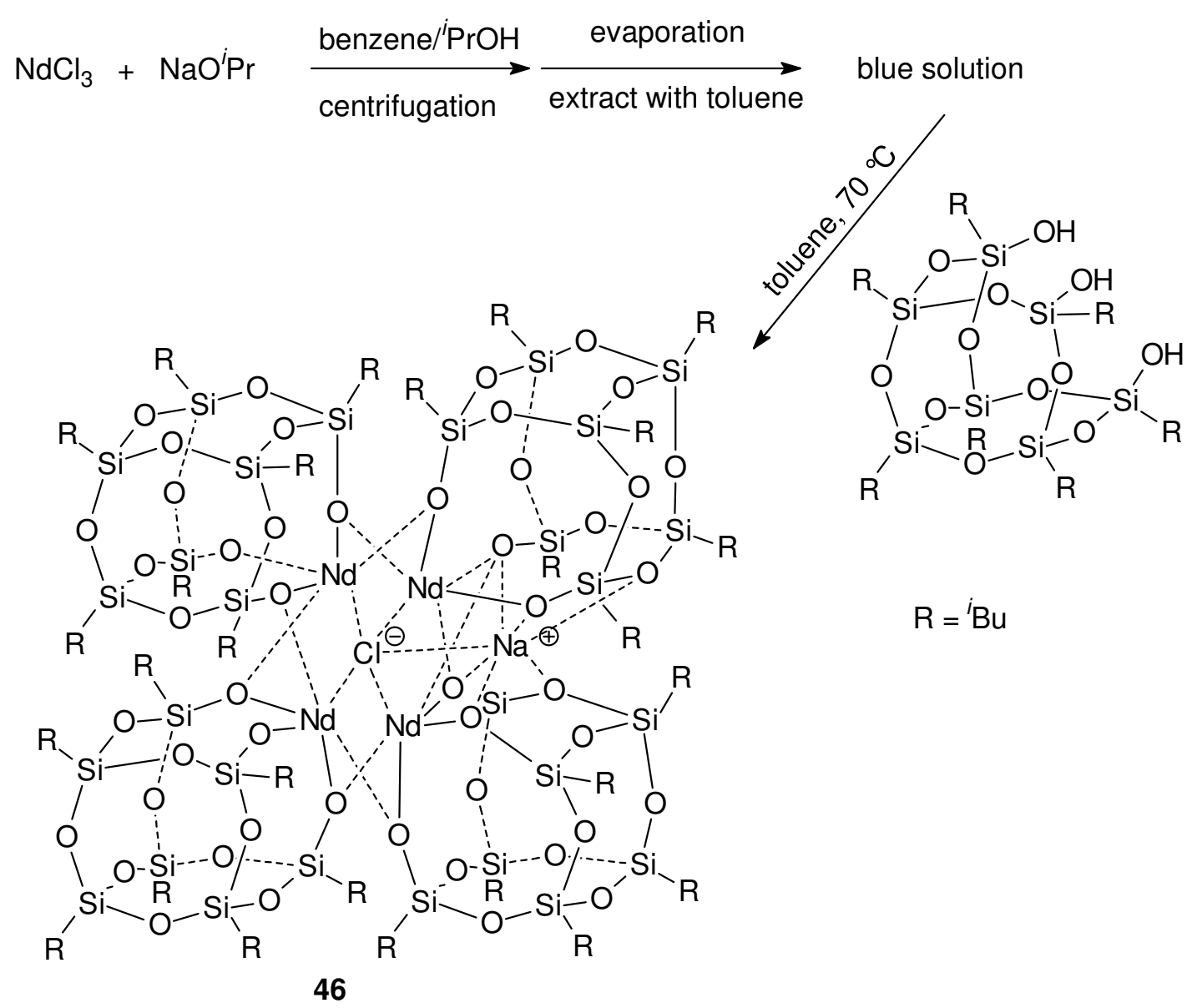

Scheme 29

As mentined above, the ytterbium bis(trimethylsilylamide) derivative $[\{(c-$ $\left.\left.\left.\mathrm{C}_{6} \mathrm{H}_{11}\right)_{7} \mathrm{Si}_{7} \mathrm{O}_{12}\right\}_{2} \mathrm{Li}_{4}\right] \mathrm{YbN}\left(\mathrm{SiMe}_{3}\right)_{2}(\mathbf{4 1}, \mathrm{Ln}=\mathrm{Yb})$ was prepared by treatment of in situ prepared 40 with anhydrous $\mathrm{YbCl}_{3}$ [43]. Surprisingly, when carried out under very similar conditions, the analogous reaction of $\mathbf{4 0}$ with anhydrous erbium trichloride took an entirely 
different course. Compound 40 was first generated by metalation of $\left(c-\mathrm{C}_{6} \mathrm{H}_{11}\right)_{7} \mathrm{Si}_{7} \mathrm{O}_{9}(\mathrm{OH})_{3}$ (29) with 3 equivalents of $\mathrm{LiN}\left(\mathrm{SiMe}_{3}\right)_{2}$, followed by reaction with anhydrous $\mathrm{ErCl}_{3}$ in $\mathrm{THF}$ (Scheme 30, Cy = cyclohexyl) [48]. Insoluble by-products were separated by extraction with $n$-pentane. Crystallization of the crude product from the same solvent afforded pale pink crystals in $65 \%$ isolated yield (determined after the crystal structure had been elucidated by X-ray diffraction). Meaningful ${ }^{1} \mathrm{H}$ and ${ }^{13} \mathrm{C}$ NMR data could not be obtained due to the paramagnetism of the $\mathrm{Er}^{3+}$ ion. The presence of eight resonances in the ${ }^{29} \mathrm{Si}$ NMR spectrum indicated a rather unsymmetrical molecular structure [48].

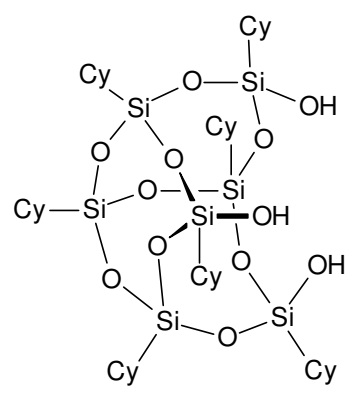

29

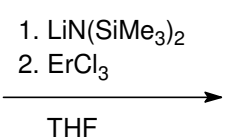

THF

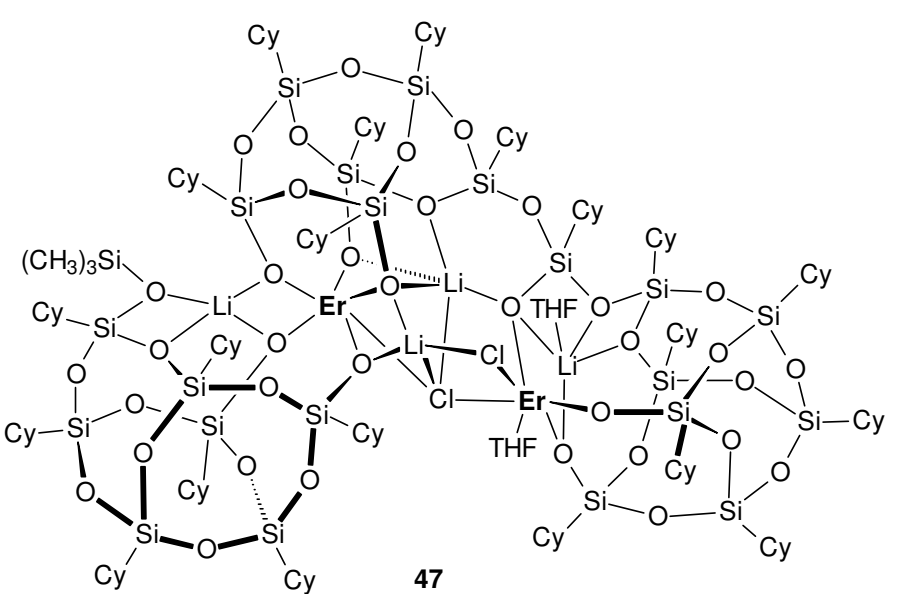

Scheme 30

An X-ray analysis of $\mathbf{4 7}$ revealed the presence of a very unsymmetrical heterobimetallic molecule as suggested by the ${ }^{29} \mathrm{Si}$ NMR data. The molecular structure of 47 comprises a large array of three silsesquioxane cages attached to two $\mathrm{Er}^{3+}$ and four $\mathrm{Li}^{+}$ ions (Fig. 11). Due to the presence of 21 cyclohexyl substituents in the periphery of the molecule, the large cluster compound is soluble even in $n$-pentane. Formally, the compound can be regarded as an "ate"-complex formed by retention of two equivalents of $\mathrm{LiCl}$ in the product. Several unexpected structural features make this large cluster molecule quite unique. Most remarkable is the coupling of two silsesquioxane cages in the coordination sphere of erbium. This results from opening of one Si-O-Si corner of the 
central silsesquioxane ligand and linking of two silsesquioxane cages through a $-\mathrm{O}_{3} \mathrm{Si}(c-$ $\left.\mathrm{C}_{6} \mathrm{H}_{11}\right)$ - unit. This leads to formation of a novel hexaanionic $\left(c-\mathrm{C}_{6} \mathrm{H}_{11}\right){ }_{14} \mathrm{Si}_{14} \mathrm{O}_{24}{ }^{6-}$ bis(silsesquioxane) ligand attached to two $\mathrm{Er}^{3+}$ and four $\mathrm{Li}^{+}$ions. The third silsesquioxane cage is formally dianionic due to trimethylsilylation of one $\mathrm{Si}-\mathrm{OH}$ functionalities. The presence of an $-\mathrm{OSiMe}_{3}$ group confirms the assumption gained from the IR data. The formation of this trimethylsilated ligand can be explained by the presence of hexamethyldisilazane, $\mathrm{HN}\left(\mathrm{SiMe}_{3}\right)_{2}$, in the reaction mixture, which is formed during the initial metalation of 29 using $\mathrm{LiN}\left(\mathrm{SiMe}_{3}\right)_{2}$. Also quite remarkably, the coordination environments of all four lithium ions in $\mathbf{4 7}$ are different, with two of them being fourcoordinate $\left(\mathrm{LiO}_{4}\right.$ and $\left.\mathrm{LiO}_{2} \mathrm{Cl}_{2}\right)$ and the other two five-coordinate $\left(\mathrm{LiO}_{5}\right.$ and $\left.\mathrm{LiO}_{4} \mathrm{Cl}\right)$ [49].

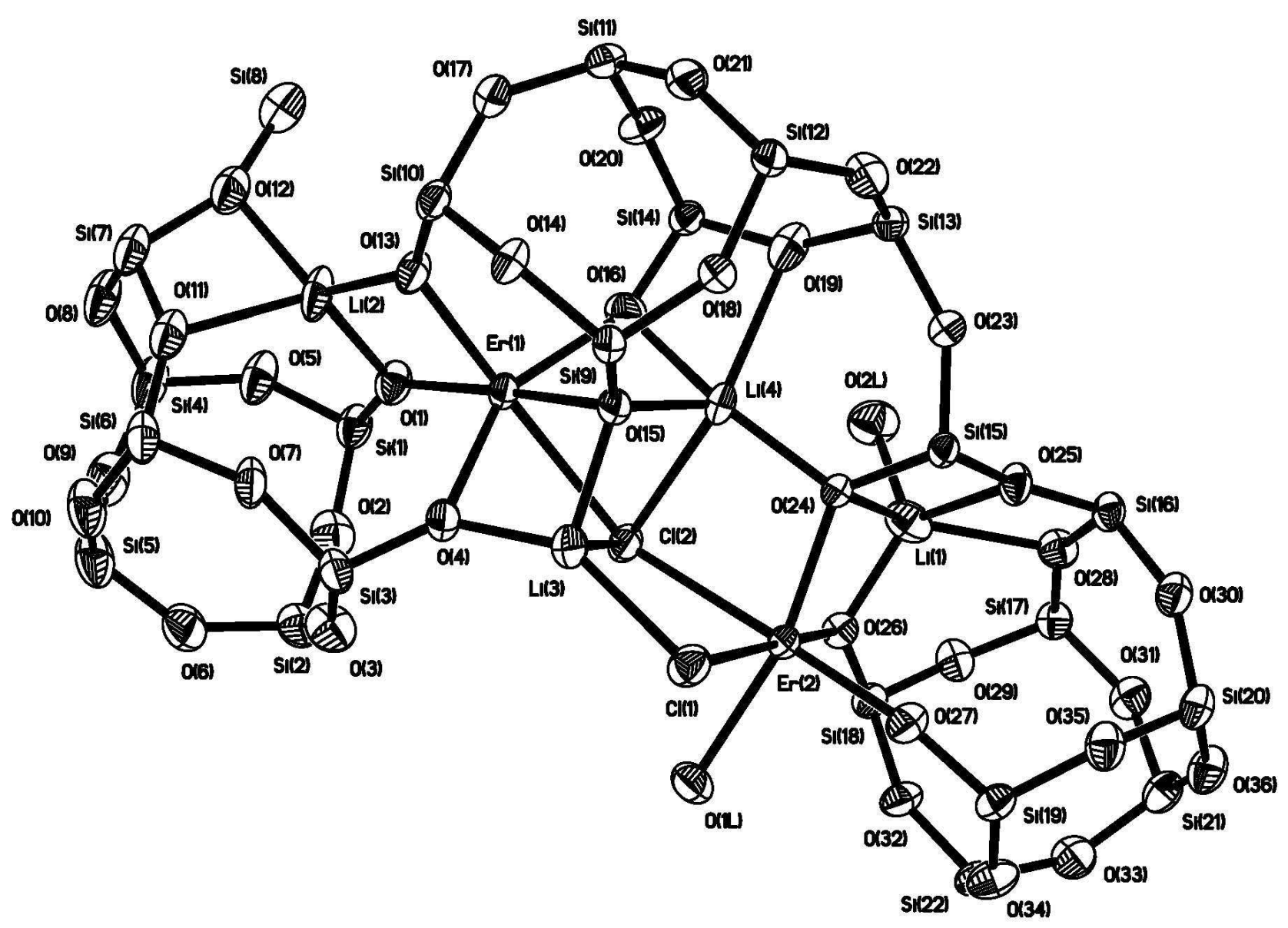

Figure 11. ORTEP view of the metallasilsesquioxane core in 47 [48] 
Treatment of $\mathrm{Ce}\left[\mathrm{N}\left(\mathrm{SiMe}_{3}\right)_{2}\right]_{3}$ with two equivalents of the disilanol $\mathrm{Cy}_{8} \mathrm{Si}_{8} \mathrm{O}_{11}(\mathrm{OH})_{2}$ (48) in diethyl ether in the presence of an excess of pyridine exclusively afforded the diamagnetic complex $\left(\mathrm{Cy}_{8} \mathrm{Si}_{8} \mathrm{O}_{13}\right)_{2} \mathrm{Ce}(\mathrm{py})_{3}$ (49). The same compound 49, albeit in somewhat lower yield, could also be prepared by direct reaction of anhydrous $\mathrm{CeCl}_{3}$ with two equivalents of $\mathbf{4 8}$ in THF/pyridine mixture (Scheme 31, Cy = cyclohexyl, py = pyridine). Quite surprisingly in both cases $\mathrm{Ce}^{3+}$ was oxidized to the tetravalent oxidation state [27].

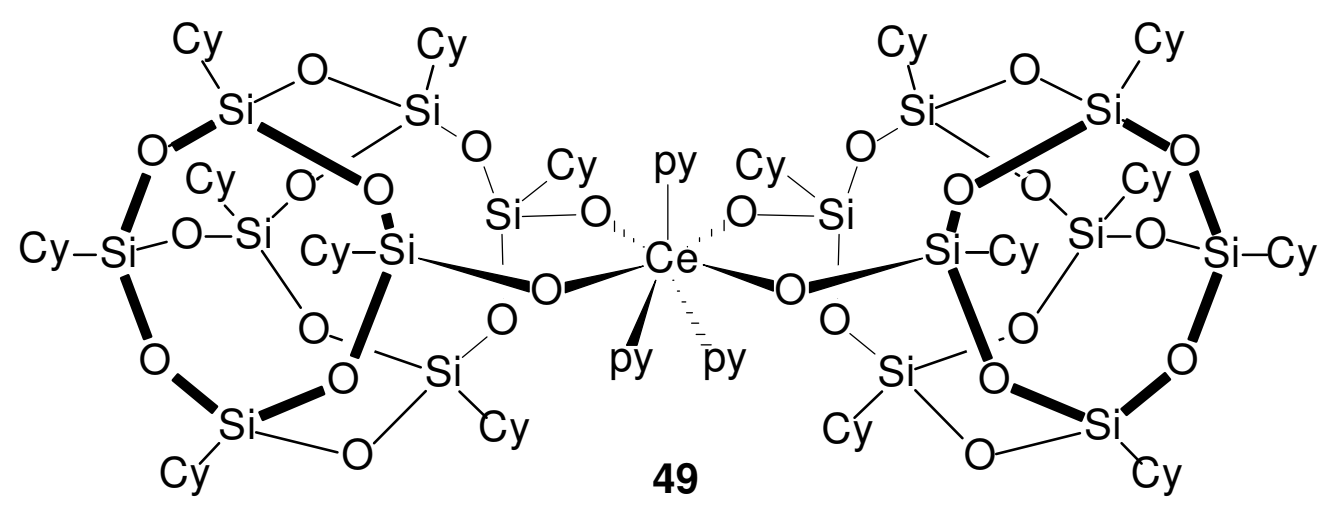

\section{Scheme 31}

Compound 49 represents the first example of a metallasilsesquioxane derived from the octameric disilanol ligand $\left[\left(c-\mathrm{C}_{6} \mathrm{H}_{11}\right)_{8} \mathrm{Si}_{8} \mathrm{O}_{13}\right]^{2-}$. The central Ce atom is coordinated by four oxygen atoms of two siloxane ligands and three nitrogens of three pyridine molecules resulting in a distorted pentagonal bipyramidal arrangement. The most striking result was certainly that despite starting from $\mathrm{Ce}^{3+}$ precursors selective formation of a $\mathrm{Ce}^{4+}$ complex occurred in all cases. A similar phenomenon has been noticed before only in the formation of $\mathrm{U}^{6+}$ silsesquioxane complexes starting from different $\mathrm{U}^{4+}$ precursors [29d]. The novel 
reaction pathway described leading to $\mathbf{4 9}$ may provide access to completely new types of metallasilasesquioxane complexes through oxidation reactions.

\section{Conclusion}

Significant progress has been made in the chemistry of disiloxanediolates and metallasilsesquioxanes of the rare earth elements. The 1,1,3,3-tetraphenyldisiloxane-1,3diolate ligand forms a variety of heterobimetallic $(\mathrm{Ln} / \mathrm{Li})$ complexes with rare earth elements. Especially the structural and derivative chemistry of heterobimetallic lanthanide bis(disiloxanediolates) has turned out to be surprisingly diverse. In the case of scandium and yttrium octahedral complexes were obtained, which according to X-ray diffraction studies can be best described as novel metallacrown complexes with the lithium disiloxanediolate ligand systems arranged in the equatorial plane and additional ligands in trans-positions. In contrast, larger lanthanide ions afford heterobimetallic disiloxanediolates which can be regarded as "inorganic metallocenes" or out-of-plane metallacrown complexes. Thus this ligand system provides a rational way to block one side of a larger lanthanide ion and, presumably, control the reactivity of the lanthanide. In addition, novel coordination modes and reaction pathways have been uncovered, which should stimulate further work in this area. Among the most remarkable new compounds are the COT-bridged inverse sandwich complex $\mathbf{1 8}$ and the first cerium(IV) disiloxanediolates $\mathbf{2 7}$ and $\mathbf{2 8 .}$

In contrast, the chemistry of lanthanide metallasilsesquioxanes is still in its infancy, although in this area too important progress has been made in recent years. Such compounds are certainly the most realistic molecular model compounds for silicasupported lanthanide catalysts. Exciting recent reports clearly indicate that silsesquioxane cages can be used to assemble unprecedented large metallasilsesquioxane clusters containing rare earth element (e.g. 46 and 47). The cerium(IV) complex 49 is still the only 
representative of its kind, although silsesquioxanes can be expected to be highly suitable ligands for tetravalent cerium. These recent findings clearly show that increased research activities in this field are highly warranted.

\section{Acknowledgements}

Our work described in this research report was generously supported by the Deutsche Forschungsgemeinschaft (DFG-Schwerpunktprogramm SPP 1166: Lanthanoidspezifische Funktionalitäten in Molekül und Material). Financial support by the Otto-von-Guericke-Universität Magdeburg is also gratefully acknowledged.

\section{References}

[1) Reviews: (a) R.Murugavel, A. Voigt, M. G. Walawalkar, H. W. Roesky, Chem. Rev. 1996, 96, 2205. (b) V.Lorenz, A. Fischer, S. Giessmann, J. W. Gilje, Yu. K. Gun'ko, K. Jacob, F. T. Edelmann, Coord. Chem. Rev. 2000, 206-207, 321. (c) R. Duchateau, Chem. Rev. 2002, 102, 3525. (d) M. M. Levitsky, B. G. Zavin, A. N. Bilyachenko, Russ. Chem. Rev. 2007, 76, 847.

[2] (a) F. Chaput, A. Lecomte, A. Dauger, J. P. Boilot, J. Mater. Chem. 1989, 1, 199. (b) M. Lazell, M. Motevalli, S. A. A. Shah, A. C. Sullivan, J. Chem. Soc., Dalton Trans. 1997, 3363.

[3] (a) A. W. Apblett, L. K. Cheatham, A. R. Barron, J. Mater. Chem. 1991, 1, 143; (b) T. Gunji, K.-I. Kubota, S.-I. Kishiki, Y. Abe, Bull. Chem. Soc. Jpn. 2002, 75, 537; (c) T. M. Gadda, W. P. Weber, Polymer Preprints 2005, 46, 801; (d) T. M. Gadda, W. P. Weber, J. Polym. Sci A 2005, 43, 2155.

[4] (a) Y. I. Yermakov, B. N. Kuznetsov, V. A. Zakharov, Catalysis by Supported Complexes, Elsevier, New York, 1981; (b) F. R. Hartley, Supported Metal Complexes, Reidel, Boston, 1985; (c) Y. Iwasawa, Ed., Tailored Metal Catalysts, 
Reidel, Boston, 1986; (d) F. T. Edelmann, Angew. Chem. 1992, 104, 600; Angew. Chem. Int. Ed. Engl. 1992, 31, 586; (e) F. J. Feher, T. A. Budzichowski, Polyhedron 1995, 14, 3239; (f) E. Lucenti, D. Roberto, C. Roveda, R. Ugo, A. Sironi, Organometallics 2000, 19, 1051; (g) G. D'Alfonso, V. Formaggio, D. Roberto, R. Ugo, E. Lucenti, L. Carlucci, Organometallics 2003, 22, 3271.

[5] (a) M. Ojeda, R. Fandos, J. L. G. Fierro, A. Otero, C. Pastor, A. Rodriguez, M. J. Ruiz, P. Terreros, J. Mol. Catal. A 2006, 247, 44; (b) R. Fandos, B. Gallego, A. Otero, A. Rodriguez, M. J. Ruiz, P. Terreros, Dalton Trans. 2007, 871.

[6] (a) M. Motevalli, D. Shah, A. C. Sullivan, J. Chem. Soc., Dalton Trans. 1993, 1849; (b) M. B. Hursthouse, M. A. Hossain, M. Motevalli, M. Sanganee, A. C. Sullivan, J. Organomet. Chem. 1990, 381, 293; (c) M. Motevalli, D. Shah, A. C. Sullivan, J. Organomet. Chem. 1996, 513, 239; (d) A. N. Bilyachenko, A. A. Korlyukov, M. M. Levitskii, M. Yu. Antipin, B. G. Zavin, Russ. Chem. Bull. 2007, 56, 543; (e) J. J. Carbo, O. Gonzalez del Moral, A. Martin, M. Mena, J.-M. Poblet, C. Santamaria, Chem. Eur. J. 2008, 7930; (f) L. Postigo, A. B. Vazquez, J. Sanchez-Nieves, P. Royo, E. Herdtweck, Organometallics 2008, 27, 5588.

[7] (a) M. A. Hossain, M. B. Hursthouse, A. Ibrahim, M. Mazid, A. C. Sullivan, J. Chem. Soc., Dalton Trans. 1989, 2347; (b) M. Motevalli, D. Shah, S. A. A. Shah, A. C. Sullivan, J. Chem. Soc., Chem. Commun. 1994, 2427; (c) M. Lazell, M. Motevalli, S. A. A. Shah, C. K. S. Simon, A. C. Sullivan, J. Chem. Soc., Dalton Trans. 1996, 1449; (d) L. King, M. Motevalli, A. C. Sullivan, Dalton Trans. 1999, 3225; (e) L. King, M. Motevalli, A. C. Sullivan, Dalton Trans. 2000, 1357.

[8] G. I. Harris, J. Chem. Soc. 1963, 5978.

[9] (a) V. Lorenz, A. Fischer, W. Brüser, F. T. Edelmann, K. Jacob, T. Gelbrich, P. G. Jones, Chem. Commun. 1998, 2217; (b) V. Lorenz, A. Fischer, K. Jacob, W. Brüser, F. T. Edelmann, Chem. Eur. J. 2001, 7, 848; (c) S. Gießmann, S. Blaurock, V. 
Lorenz, F. T. Edelmann, Inorg. Chem. 2007, 46, 8100; (d) S. Gießmann, S. Blaurock, V. Lorenz, F. T. Edelmann, Inorg. Chem. 2007, 46, 10383; (e) S. Gießmann, S. Blaurock, V. Lorenz, F. T. Edelmann, Inorg. Chem. 2007, 46, 10956; (f) S. Gießmann, S. Blaurock, F. T. Edelmann, Z. Anorg. Allg. Chem. 2008, 634, 186; (g) A. Edelmann, S. Blaurock, C. Hrib, F. T. Edelmann, J. Organomet. Chem. 2010, 695, 1026; (h) V. Lorenz, A. Edelmann, S. Blaurock, C. Hrib F. T. Edelmann, Compt. Rend. Chim. 2010, in print; (i) V. Lorenz, S. Blaurock, C. G. Hrib, F. T. Edelmann, Dalton Trans. 2010, in print.

[10] S. Gießmann, S. Blaurock, A. Edelmann, V. Lorenz, F. T. Edelmann, Z. Anorg. Allg. Chem. 2008, 634, 2459.

[11] (a) H. Schumann, J. A. Meese-Marktscheffel, L. Esser, Chem. Rev. 1995, 95, 865. (b) F. T. Edelmann, "Complexes of Scandium, Yttrium and Lanthanide Elements", in Comprehensive Organometallic Chemistry III, (Eds.: R. H. Crabtree, D. M. P. Mingos), Elsevier, Oxford, 2006, 1.

[12] (a) S.-L. Zhou, S.-W. Wang, G.-S. Yang, X.-Y. Liu, E.-H. Sheng, K.-H. Zhang, L. Cheng, Z.-X. Huang, Polyhedron 2003, 22, 1019. (b) B. Martin-Vaca, A. Dumitrescu, H. Gornitzka, D. Bourissou, G. Bertrand, J. Organomet. Chem. 2003, $682,263$.

[13] A. Recknagel, A. Steiner, M. Noltemeyer, S. Brooker, D. Stalke, F. T. Edelmann, J. Organomet. Chem. 1991, 414, 327.

[14] S. Anfang, T. Grob, K. Harms, G. Seybert, W. Massa, A. Greiner, K. Dehnicke, Z. Anorg. Allg. Chem. 1999, 625, 1853.

[15] D. Cui, M. Nishiura, Z. Hou, Angew. Chem. Int. Ed. 2005, 44, 959.

[16] F. Mares, K. O. Hodgson, A. Streitwieser, Jr., J. Organomet. Chem. 1971, 28, C24.

[17] H. Schumann, J. Winterfeld, L. Esser, G. Kociok-Köhn, Angew. Chem, Int. Ed. 1993, 32, 1208. 
[18] W. J. Evans, M. A. Johnston, R. D. Clark, R. Anwander, J. W. Ziller, Polyhedron 2001, 20, 2483.

[19] G. E. Coates, R. A. Whitcombe, J. Chem. Soc. 1956, 3351.

[20] G. Mann, H. Olapinski, R. Ott, J. Weidlein, Z. Anorg. Allg. Chem. 1974, 410, 195.

[21] (a) R. M. C. Carrijo, J. R. Romero, Quimica Nova 2000, 23, 331; (b) A. K. Das, Coord. Chem. Rev. 2001, 213, 307; (c) V. Nair, L. Balagopal, R. Rajan, J. Mathew, Acc. Chem. Res. 2004, 37, 21; (d) J. Dziegiec, S. Domagala, Trends Inorg. Chem. 2005, 8,43 .

[22] (a) M. Komiyama, Metal Ions Biol. Syst. 2003, 40, 463; (b) Y. Yamamoto, M. Komiyama, Materials Integration 2005, 19, 55.

[23] H. Jian, X. Zhou, D. Zhao, Huaxue Shiji 2006, 28, 279.

[24] Metal Ions in Biological Systems (Eds.: A. Sigel, H. Sigel,), Marcel Dekker, Inc., New York, Basel, 2003, Vol. 40.

[25] (a) D. C. Bradley, H. Holloway, Can. J. Chem. 1962, 40, 1176; (b) A. Sen, H. A. Stecher, A. L. Rheingold, Inorg. Chem. 1992, 31, 473; (c) L. G. Hubert-Pfalzgraf, N. El Khokh, J. C. Daran, Polyhedron 1992, 11, 59; (d) L. G. Hubert-Pfalzgraf, H. Guillon, Appl. Organomet. Chem. 1998, 12, 221; (e) S. Suh, J. Guan, L. A. Miinea, J.-S. M. Lehn, D. M. Hoffman, Chem. Mater. 2004, 16, 1667.

[26] P. S. Gradeff, K. Yünlü, A. Gleizes, J. Galy, Polyhedron 1989, 8, 1001.

[27] Yu. K. Gun'ko, R. Reilly, F. T. Edelmann, D. Stalke Angew. Chem. Int. Ed. 2001, $40,1279$.

[28] (a) W. J. Evans, T. J. Deming, J. W. Ziller, Organometallics 1989, 8, 1581; (b) W. J. Evans, T. J. Deming, J. M. Olofson, J. W. Ziller, Inorg. Chem. 1989, 28, 4027; (c) W. J. Evans, L. A. Edinger, J. W. Ziller, Polyhedron 1999, 18, 1475.

[29] (a) V. Lorenz, A. Fischer, S. Gießmann, J. W. Gilje, Yu. Gun'ko, K. Jacob, F. T. Edelmann, Coord. Chem. Rev. 2000, 206-207, 321; (b) R. Duchateau, Chem. Rev. 
2002, 102, 3525; (c) R. W. J. M. Hanssen, R. A. van Santen, H. C. L. Abbenhuis, Eur. J. Inorg. Chem. 2004, 675; (d) V. Lorenz, F. T. Edelmann, Adv. Organomet. Chem. 2005, 53, 101.

[30] H. C. L.Abbenhuis, Chem. Eur. J. 2000, 6, 25.

[31] P. G. Harrison, J. Organomet. Chem. 1997, 542, 141.

[32] J. D. Lichtenhan, Comments Inorg. Chem. 1995, 17, 115.

[33] F. J. Feher, D. A. Newman, J. F. Walzer, J. Am. Chem. Soc. 1989, 111, 1741.

[34] M. G. Voronkov, V. L. Lavrentyev, Top. Curr. Chem. 1982, 102, 199.

[35] F. J. Feher, T. A. Budzichowski, R. L. Blanski, K. J. Keller, J. W. Ziller, Organometallics 1991, 10, 2526.

[36] F. J. Feher, T. A. Budzichowski, Polyhedron 1995, 14, 3239.

[37] T. W. Hambley, T. Maschmeyer, A. F. Masters, Appl. Organomet. Chem. 1992, 6, 253.

[38] J. R. Severn, R. Duchateau, R. A. van Santen, D. D. Ellis, A. L. Spek, G. P. A. Yap, Dalton Trans. 2003, 2293.

[39] W. A. Herrmann, R. Anwander, V. Dufaud, W. Scherer, Angew. Chem. Int. Ed. Engl. 1994, 33, 1285.

[40] J. Annand, H. C. Aspinall, J. Chem. Soc., Dalton Trans. 2000, 1867.

[41] J. Annand, H. C. Aspinall, A. Steiner, Inorg. Chem. 1999, 38, 3941.

[42] P. L. Arnold, A. J. Blake, S. N. Hall, B. D. Ward, C. Wilson, Dalton Trans. 2001, 488.

[43] V. Lorenz, S. Gießmann, Y. K. Gun'ko, A. K. Fischer, J. W. Gilje, F. T. Edelmann, Angew. Chem. Int. Ed. 2004, 43, 4603.

[44] V. Lorenz, A. Fischer, F. T. Edelmann, J. Organomet. Chem. 2002, 647, 245.

[45] R. Duchateau, H. C. L. Abbenhuis, R. A. van Santen, S. K.-H. Thiele, M. F. H. van Tol, Organometallics 1998, 17, 5222. 
[46] W. E. Piers, E. E. Bunel, J. E. Bercaw, J. Organomet. Chem. 1991, 407, 51.

[47] G. Wu, Y. Chen, D.-J. Xu, J.-C. Liu, W. Sun, Z. Shen, J. Organomet. Chem. 2009, 694, 1571.

[48] V. Lorenz, S. Blaurock, C. G. Hrib, F. T. Edelmann, Eur. J. Inorg. Chem. 2010, in print. 


\section{Biographical Sketch}

Frank T. Edelmann was born in Hamburg, Germany, in 1954. He studied chemistry at the University of Hamburg, where he obtained his diploma degree in 1979 and $\mathrm{PhD}$ in 1983 under the guidance of Prof. Ulrich Behrens. After 2 years of postdoctoral research with Josef Takats (University of Alberta), John W. Gilje (University of Hawaii) and Tristram Chivers (University of Calgary) he finished his habilitation at the University of Göttingen in 1991 in the group of Herbert W. Roesky. In 1995 he was appointed Full Professor of Inorganic Chemistry at the Otto-von-Guericke-University in Magdeburg. His main research interests are in organolanthanide and -actinide chemistry, silicon chemistry (silsesquioxanes and metallasilsesquioxanes), and fluorine chemistry. His work is documentated in over 280 scientific papers, 2 books and several patents. In 2008 he was awarded the "Terrae Rarae 2008 Award" for his "eminent work in coordination chemistry of the rare earth elements".

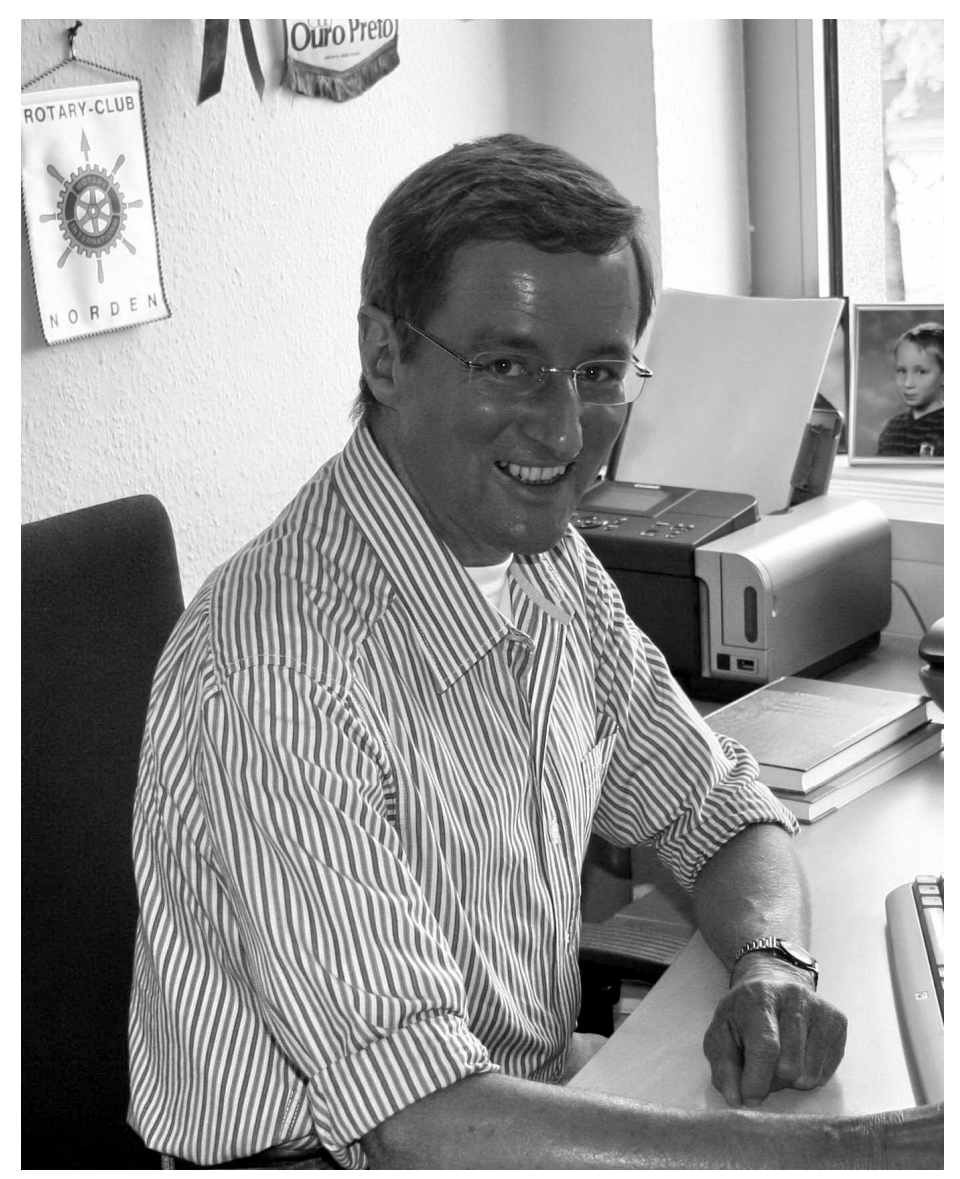




\section{Entry for the Table of Contents}

Recent results in the chemistry of lanthanide disiloxanediolates and metallasilsesquioxanes are reviewed. Both classes of compounds can be regarded as realistic model compounds for silica-supported lanthanide catalysts.

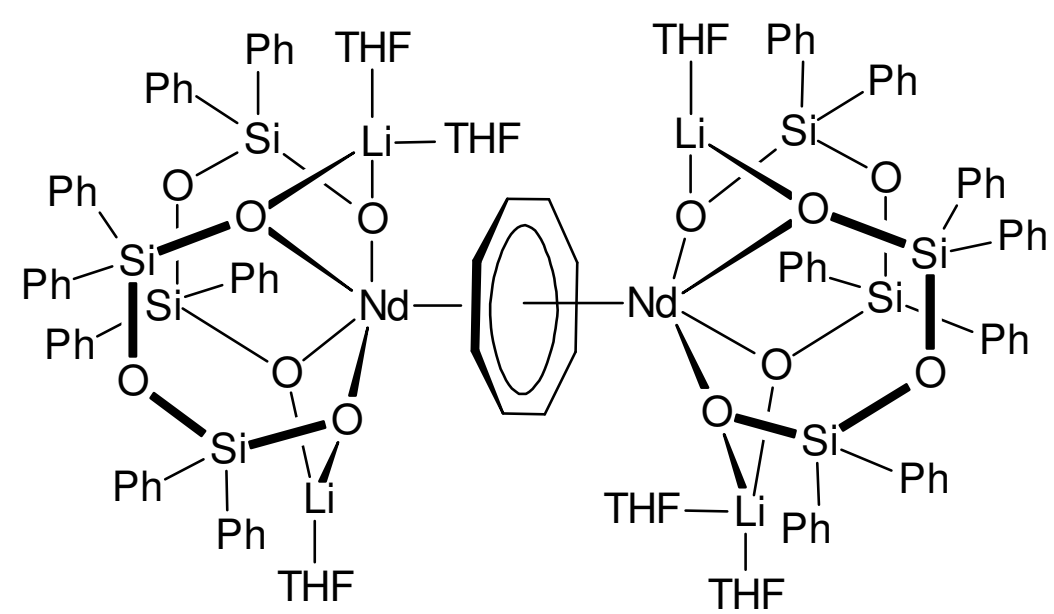

